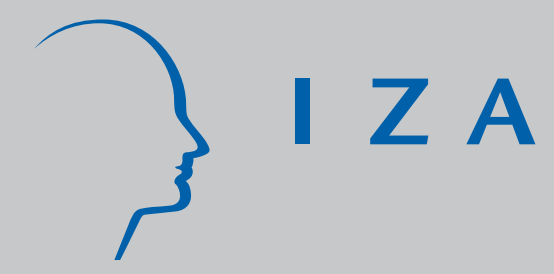

IZA DP No. 4025

\title{
Persistencies in the Labour Market
}

\author{
Paul Frijters \\ Maarten Lindeboom \\ Gerard J . van den Berg
}

February 2009 


\title{
Persistencies in the Labour Market
}

\author{
Paul Frijters \\ Queensland University of Technology \\ and Australian National University \\ Maarten Lindeboom \\ VU University Amsterdam, \\ HEB Bergen, Netspar and IZA
}

Gerard J. van den Berg

VU University Amsterdam, IFAU-Uppsala, Netspar, IFS, CEPR and IZA

\section{Discussion Paper No. 4025 \\ February 2009}

\author{
IZA \\ P.O. Box 7240 \\ 53072 Bonn \\ Germany \\ Phone: +49-228-3894-0 \\ Fax: +49-228-3894-180 \\ E-mail: iza@iza.org
}

\begin{abstract}
Any opinions expressed here are those of the author(s) and not those of IZA. Research published in this series may include views on policy, but the institute itself takes no institutional policy positions.

The Institute for the Study of Labor (IZA) in Bonn is a local and virtual international research center and a place of communication between science, politics and business. IZA is an independent nonprofit organization supported by Deutsche Post Foundation. The center is associated with the University of Bonn and offers a stimulating research environment through its international network, workshops and conferences, data service, project support, research visits and doctoral program. IZA engages in (i) original and internationally competitive research in all fields of labor economics, (ii) development of policy concepts, and (iii) dissemination of research results and concepts to the interested public.
\end{abstract}

IZA Discussion Papers often represent preliminary work and are circulated to encourage discussion. Citation of such a paper should account for its provisional character. A revised version may be available directly from the author. 


\section{ABSTRACT}

\section{Persistencies in the Labour Market ${ }^{*}$}

Using longitudinal income-tax registers, we study how past labour market outcomes affect current labour market transition rates. We focus on hysteresis effects of the durations and incidence of previous spells out of work. We estimate flexible multi-state Mixed Proportional Hazard specifications for transition rates between employment, unemployment, and welfare/non-participation. Our main finding is that after longer periods of employment with high income, individuals' transition rates from unemployment to employment increase. Longer periods of non-employment generally decrease future transition rates to work, and sometimes also from work. The quantitative magnitude of persistency and hysteresis effects on inequality is modest.

JEL Classification: J64, J22, C41

Keywords: duration analysis, hysteresis, inequality, wages, unemployment, hazard rates, employment, income, work

Corresponding author:

Paul Frijters

Queensland University of Technology

Z-block

School of Economics

2 George Street

GPO box 2434

Brisbane, Qld 4001

Australia

E-mail: paul.frijters@anu.edu.au

\footnotetext{
* We thank Pierre Koning, Michiel van Leuvensteijn, Vincent Thio, and Tiemen Woutersen, for helpful comments. Thanks to Statistics Netherlands (CBS) and the Dutch Ministry of Social Affairs for their permission to use a subset of the Dutch Income Panel Data Register. We also thank the Ministry for financial support, and we thank Coen Teulings and Jan Koeman for their encouragement.
} 


\section{Introduction}

In this paper we study the relationships between labour market outcomes and subsequent labour market transitions. This means that we try to account for the fact that future labour market opportunities change during the labour market career of an individual. Some individuals may gain job-seeking skills through an expanding network of individuals who can be called upon whenever a job is lost. Other individuals lose job-finding skills when they become demotivated after long periods without a job or when they become stigmatised or isolated. There are many other ways in which current labour market outcomes of an individual can affect future opportunities. Such dynamic chains may include many variables, like wages, benefit levels, and even marriage prospects, but we focus our attention to transition rates between labour market states.

We label the relationships between labour market outcomes and subsequent labour market transitions persistencies. The term persistency has sometimes been used to describe the stability of equilibria, or negative feedback loops of unemployment. Here the term is used for any causal relationship between previous individual labour market outcomes and current labour market opportunities. Persistencies are of importance for the functioning of the economy. First, they may involve changes in human capital. Persistencies that reduce human capital, such as a loss of skills during long periods of unemployment, thereby affect the allocation of individuals in the entire economy and affect the wealth of the entire population. Policies can be designed to target those groups suffering most from loss of skills.

Because the persistencies affect future labour market states, they also impact upon the distribution of unemployment and employment in the economy, which raises issues of allocation. Labour market states can impact on other areas of life, such as social networks or community cohesion. Apart from this wider interest, the interest in persistencies is also driven by a simple desire to understand the workings of the labour market.

One specific type of persistency that has attracted a lot of attention in the economic literature is the effect of longer spells of unemployment on future transition rates. In the hysteresis literature (see e.g. the 25 mentioned articles in Røed, 1997), several mechanisms are suggested through which spells of unemployment negatively affect future labour market outcomes. One is the classic argument of Phelps (1972) that individuals lose their skills during unemployment, which negatively affects future possibilities of finding a job. If a region is hit by a negative shock that causes a high level of unemployment, such a loss of skills can 
worsen the ensuing recession or at least delay economic recovery. This line of reasoning was advanced by Ljungqvist and Sargent (1998), who try to explain European unemployment levels: the generous social security payments in much of Europe increase unemployment durations, which increases the exposure of the unemployed to a possible loss of skills. In this way, the generous social security payments in Europe were argued to aggravate, especially in volatile economic periods, the negative effects of loss of skills during unemployment. Other mechanisms known in the literature through which there are negative effects of longer spells of unemployment on future transition rates to employment are discouragement, stigma, or an adaptation of social norms (e.g. Piore, 1971; or Lindbeck, 1995).

Much of the older empirical literature on hysteresis uses aggregate data. One popular approach has been to look at whether unemployment rates follow a random walk. If they do, then the current unemployment rate can be seen as the best predictor of the future unemployment rate, and there would then be no tendency of the economy to move to any 'natural rate' (see Røed, 1997). Obviously, this method has its flaws as there are upper and lower bounds on the level of unemployment and the hypothesis of a random walk is somewhat extreme. As is argued in Røed (1997), it seems more realistic to suppose that there is a high degree of persistence of the current unemployment rate. Another drawback is that aggregate unemployment rates give no evidence for a particular mechanism driving the persistence.

By now there is also a substantial empirical literature using individual records to study the effect of past individual unemployment durations on individual transition rates, notably the transition rate from unemployment to work. The main econometric challenge is to disentangle the causal effect from spurious selection effects due to unobserved individual characteristics. If an individual has a low future transition rate to employment, this may either be due to what happened before or to an unobserved individual trait that also influenced past outcomes. Existing studies typically deal with this by resorting to random-effects specifications with time-invariant unobserved traits that are orthogonal to observed characteristics. ${ }^{1}$ We briefly list a few previous findings. Heckman and Borjas (1980) study the labour market careers of 122 individuals with multiple unemployment spells. They find no effect of previous unemployment spells on current transition rates from unemployment to employment. Using a much larger data

\footnotetext{
${ }^{1}$ See Magnac (2000) and D'Addio and Honoré (2002) for alternative approaches with individual-specific fixed effects (allowed to be correlated to the observed characteristics) in discrete-time settings.
} 
set, Lynch $(1985,1989)$ also finds no effects. Her estimates vary sharply with the assumed functional form of the unobserved heterogeneity distribution. Omori (1997), who studies the careers of 2184 young men drawn from the US National Youth Longitudinal Study, does find that longer periods without employment lead to lower future transition rates to employment, which he attributes to a stigma effect. Blau (1994) also studies unemployment persistencies but focuses exclusively on older men. For additional micro-econometric studies, see Gregg (2001) and Burgess et al. (2003), who both focus on younger individuals, Arulampalam (2002), and Choi and Shin (2002). The previous studies have all provided major contributions to the understanding of persistency as an empirical phenomenon, and they have been influential in policy debates. At the same time one may argue that the model frameworks are in one sense or another more restrictive than ours (see below).

A full-blown empirical analysis of "persistency" effects on all possible labour market transitions is a formidable task. Reliable estimation of unemploymentrelated persistencies requires large numbers of individuals who experience unemployment more than once. The measurement of unemployment incidence and duration should be precise. Clearly, if the number of previous spells is a relevant determinant of future outcomes then the data should contain accurate measurements of this number. Reliable inference also requires the researcher to address the initial-conditions problems that plague the dynamic analysis of causal effects of lagged endogenous variables. Moreover, it is important that income variables are reliably observed as well, because otherwise one may overlook potentially relevant model determinants, leading to omitted-variable biases. Similarly, we need to observe employment spells and non-participation spells, to deal with persistencies running through employment and non-participation, and to deal with right-censoring due to finiteness of the observation window.

In this paper we use a data set with features that allow us to deal with these requirements to a high degree. This data set is the Dutch IPO register, which is based on income tax records. The data set contains labour market outcomes of about 65000 individuals aged between 14 and 55 over nine years, covering the time period 1989-1997. There are four major advantages of using such register data (as opposed to surveys). One is that there is no non-response or attrition outflow apart from death and migration, and that the inflow is random. Hence sample selectivity, which is often considerable in longitudinal surveys, is not an issue with administrative data. Another advantage is that we avoid the problems of recall with respect to previous transitions: individuals are likely to underreport the incidence of short spells in surveys. This issue was investigated by 
Albaek and Larsen (1993) who were able to compare register data with survey data on the same set of Danish individuals. Their finding was that register data include about double the number of (unemployment) spells, mainly because they include many interruptions to the periods of unemployment that individuals themselves did not mention. The third advantage of register data is that they often have superior measurements of the income of individuals, because the recall of individuals regarding their incomes is very unlikely to be better than the information from the tax authorities. A final advantage is that register data sets are often very large. This is also the case with the administrative data set used in this paper, which covers about 65000 adults. Because of this large size, we can afford to look only at the new entrants into the sample, which allows us to avoid initial conditions problems as well, i.e., the large sample size means we can avoid using people for whom we do not know the full labour market history.

We hence use the 4897 individuals whose entrance into the labour market we can observe. Extensive information is available about the sources of incomes and household composition of individuals over the observation window. The large number of individuals and spells enables us to distinguish between three possible labour market states, whereas in most analyses mentioned only employment and non-employment is discerned. Allowing for employment, unemployment and non-participation results in about 15000 spells, with a large variety of observed individual careers. In Section 2, we extensively examine the characteristics of this data set, and we explain the choices we make to operationalise the three labour market states. The transition rates between employment, unemployment, and non-participation are then analysed with an extension of the Mixed Proportional Hazard model. For a survey of this type of model, see Van den Berg (2001).

In Section 3 we present model specifications based on different assumptions about the unobserved heterogeneity distribution and on the endogeneity of individual income. From standard search theory it would seem very likely that transition rates are intimately connected with earnings potential (and hence actual incomes) because earnings potential affects reservation wages and hence the probability of finding acceptable offers. An ad-hoc analysis in the Appendix indeed suggests endogeneity of incomes. The data do not allow for a structural analysis though, because we lack some essential information (such as benefit entitlement) needed to model individual choices. We hence deal with endogeneity by presenting a sequence of specifications in which we ignore income as an explanatory variable and a sequence of specifications in which we include income and ignore the possible endogeneity. In this way we can at least get a good idea as to the robustness of the found persistencies, and in the process qualitatively 
assess the seriousness of the endogeneity of income.

After discussing the differences in specification in Section 3, we try to clarify the findings by a simulation study in which we turn off persistence effects to compute the net effect of persistencies on the participation rates of the whole population. We use these simulations to analyse the determinants of inequality in unemployment duration and in cumulative incomes. Following these simulations, we look at the effect of alternative assumptions on the unobserved heterogeneity distribution. The final section concludes.

\section{Data and method}

\subsection{Method}

We model the rate that an individual makes a transition after a duration $t$ in the current state, given that that individual has not yet made the transition. This amounts to modelling the transition rates $\theta_{j}^{k}$ from state $k$ to state $j$. Here, $k$ and $j$ are taken from the set $\{e, u, n\}$, where $e$ stands for employment, $u$ stands for unemployment and $n$ for non-participation. We use the popular Mixed Proportional Hazard specification. This allows for a baseline hazard $\lambda(t)$ through which the transition probability changes with the elapsed duration of a spell. Furthermore, the model allows for an unobserved heterogeneity value $v$ which affects the transition rate multiplicatively at each time period and which is orthogonal to observed individual characteristics. We sketch the specification of the hazard rate for a particular individual for the transition from unemployment to work, where the other 5 hazard rates are defined analogously:

$$
\theta_{e}^{u}(t \mid v, x, \tau, h)=\lambda(t) \cdot c(\tau+t) \cdot v \cdot e^{x^{\prime} \beta+h \gamma}
$$

$\theta_{e}^{u}(t \mid v, x, \tau, h)$ is the hazard rate from unemployment to employment given unobserved individual characteristic $v$, a set of observed individual characteristics $x$ that may differ for each spell, a calendar time of entry $\tau$ into unemployment, and a set of variables describing past labour market outcomes $h$. On the right-hand side, $c(\tau+t)$ is a non-negative time-varying function that allows for the fact that hazard rates can be different over seasons due to demand factors.

We take a non-parametric specification for the baseline function $\lambda(t)$ by allowing for a fixed value $\lambda(t)$ within a time interval, and allowing for different values in different time intervals. By taking suitable intervals, we can thereby allow for a very flexible shape of the baseline hazard. $\beta$ and $\gamma$ are parameters that relate to the individual characteristics and the outcome of previous spells. 
Given that we do not observe the unobserved heterogeneity component, we have to integrate it out to obtain a likelihood. An example: the likelihood of observing a single duration of $T$ in a spell of unemployment ending in employment is

$$
\int \theta_{e}^{u}(T \mid v, x, \tau, h) e^{-\int_{0}^{T} \theta_{e}^{u}(t \mid v, x, \tau, h) d t} e^{-\int_{0}^{T} \theta_{n}^{u}(t \mid v, x, \tau, h) d t} d G(v)
$$

where $G(v)$ denotes the distribution of $v$ and the integral should be read in the Lebesque sense. In this likelihood, $e^{-\int_{0}^{T} \theta_{e}^{u}(t \mid v, x, \tau, h) d t}$ equals the probability of not making a transition to employment before $T ; e^{-\int_{0}^{T} \theta_{n}^{u}(t \mid v, x, \tau, h) d t}$ is the probability of not making a transition to non-participation before $T$; and $\theta_{e}^{u}(T \mid v, x, \tau, h)$ is the conditional rate of making a transition to employment at $T$. If we would observe one spell of unemployment ending in employment and a censored spell in employment, the likelihood would become

$$
\begin{aligned}
& \int \theta_{e}^{u}\left(T_{1} \mid v, x_{1}, \tau_{1}, h_{1}\right) e^{-\int_{0}^{T_{1}} \theta_{e}^{u}\left(t \mid v, x_{1}, \tau_{1}, h_{1}\right) d t} e^{-\int_{0}^{T_{1}} \theta_{n}^{u}(t \mid v, x, \tau, h) d t} * \\
& e^{-\int_{0}^{T_{2}} \theta_{u}^{e}\left(t \mid v, x_{2}, \tau_{2}, h_{2}\right) d t} e^{-\int_{0}^{T_{2}} \theta_{n}^{e}\left(t \mid v, x_{2}, \tau_{2}, h_{2}\right) d t} d G(v)
\end{aligned}
$$

where the subscript 1 refers to the values in the first spell and the subscript 2 for the values in the second spell. Here the terms in the first line are as before, but the term $e^{-\int_{0}^{T_{2}} \theta_{u}^{e}\left(t \mid v, x_{2}, \tau_{2}, h_{2}\right) d t} e^{-\int_{0}^{T_{2}} \theta_{n}^{e}\left(t \mid v, x_{2}, \tau_{2}, h_{2}\right) d t}$ in the second line equals the probability of not going from employment to either unemployment or non-participation before $\mathrm{T}_{2}$. The likelihood of even more spells is constructed analogue. Given that the maximum number of spells observed in our data set is 22 one can see that the expressions become rather involved.

A major issue is the specification of the distribution of $v$. Here we take a flexible non-parametric approach by taking a distribution with a fixed number of mass-points. For the transition of unemployment to work this means we allow $v$ to take on the values $\left\{v_{1}, . ., v_{M}\right\}$. Although we will show the likelihood of specifications in which $\mathrm{M}=2$, which is the most common specification in the literature, using Akaike's information criterion ${ }^{2}$ the final specifications all have $\mathrm{M}=3$. These means we allow $v$ to take on the values $\left\{v_{1}, v_{2}, v_{3}\right\}$. Because there are 6 possible transitions, this means we have $6^{*} 3=18$ heterogeneity values. Figures 1 and 2 show two possible ways of dealing with the probability mass points of these heterogeneity values: In both figures, the superscripts identify the transition

\footnotetext{
${ }^{2}$ Akaike's information criterion is to take the model that maximises $\mathrm{AIC}(\mathrm{C})=-2 \ln L_{c}+2 N_{c}$ (with $\mathrm{C}$ the number of points of support and $N_{c}$ the number of parameters to be estimated).
} 
involved. Hence, $v_{3}^{b}$ means the third possible unobserved heterogeneity value of the transition from employment to unemployment.

In Figure 1 we assume that the unobserved individual traits only lead to three different possible effects. Hence, there are only three possible combinations of heterogeneity values for the six transitions: $\left[v_{1}, v_{1}^{a}, v_{1}^{b}, v_{1}^{c}, v_{1}^{d}, v_{1}^{f}\right],\left[v_{2}, v_{2}^{a}, v_{2}^{b}, v_{2}^{c}, v_{2}^{d}, v_{2}^{f}\right]$, and $\left[v_{3}, v_{3}^{a}, v_{3}^{b}, v_{3}^{c}, v_{3}^{d}, v_{3}^{f}\right]$.

In Figure 2 we allow for any combination between the three allowed pairs $\left\{v, v^{a}\right\}$, the three allowed pairs $\left\{v^{b}, v^{c}\right\}$, and the three allowed pairs $\left\{v^{d}, v^{f}\right\}$, leading to 27 probability points. This second specification allows for much more flexible patterns of unobserved heterogeneity but comes at the expense of more parameters to be estimated. A specification in which any combination of the six heterogeneity values is allowed (with nine possible pairs of $\left\{v, v^{a}\right\}$, etc.) exceeds the data-possibilities. Sensitivity analyses regarding alternative choices for this heterogeneity distribution will be shown.

We impose no restrictions on the values of the heterogeneity points (no onefactor loading). This avoids the problem identified by Lindeboom and Van den Berg (1994) of one-factor loading models that they implicitly assume a fixed relationship between the variance of each marginal heterogeneity distribution and the correlation structure between the heterogeneity distributions of the different states. See Van den Berg (2001) for a general overview of identification results for single-state and multi-state duration models.

\subsection{Data}

About $6 \%$ of the tax-records of the Dutch population (randomly selected) in the period January 1, 1989, through December 31, 1997, are stored in the Income Panel data base (IPO). Simple sample characteristics and basic analyses of this data base can be found in De Koning et al. (1998). Because of the confidential nature of income tax records, only few international publications have used the IPO data (see e.g. Van Leeuwen and Pannekoek, 2002, Atkinson and Salverda, 2005, Manting and Bouman, 2006, and Van Vuren and Van Vuuren, 2007).

The data include information on all the labour market spells of about 65000 adults aged 15 to 55. A spell indicates a particular 'source of income', of which there are 15 [\% of the whole population in this income source in brackets]:

1. Only wages $[33 \%]$

2. Unemployment benefit [4\%]

3. Special unemployment benefit [3\%] 
4. $2+$ wage income $[4 \%]$

5. $3+$ wage income $[1.5 \%]$

6. $2+$ non-wage income (such as alimony or welfare) $[1 \%]$

7. $3+$ non-wage income $[0.2 \%]$

8. welfare benefits $[2 \%]$

9. 8 +wage income $[1 \%]$

10. $8+$ non-wage income $[0.2 \%]$

11. disability benefits $[2.5 \%]$

12. $11+$ wage income $[1 \%]$

13. $11+$ non-wage income $[0.5 \%]$

14. other incomes (such as alimony or profits) [19\%]

15. no income $[27 \%]$

In order to see how we might reduce these 15 sources of income into three states, some background information on the Dutch benefit system is necessary.

All Dutch inhabitants are entitled to welfare benefits if they do not have paid employment or if their paid employment does not suffice to reach a legal minimum. Individuals who have never worked before are therefore entitled to benefit payments, possibly augmented with a child-support allowance to which all child-rearing families are entitled. Most other benefits are related to an employment history: the more hours of work spent in employment, the longer the subsequent entitlement to unemployment benefits. Also, for workers there is a disability allowance system by which individuals who become disabled obtain a fixed percentage of their last-earned income in benefits until the legal retirement age of 65 . At 65 , all individuals obtain a state pension, augmented with whatever they have provided for themselves or was provided for via pre-paid employment related pensions. A peculiarity of the Dutch system is that there are many 'grey states' in the benefit system. It is for instance possible that someone has been declared 'disabled' for $50 \%$. This means he or she is entitled to $50 \%$ of the benefit for disability and may simultaneously enjoy an unemployment benefit or an income from a job in which the individuals works a fraction of the time. Other 
'grey states' are that individuals can receive benefits together with alimony payments or capital incomes. Unfortunately, the data only has reliable information on which sources of income an individual has, not on the relative importance of each source.

Now, it is the case that most of the groups that hardly search for jobs, and whom we might label as non-participants, either have no source of income or receive different benefits than unemployment benefits: persons who are supported by the income of someone else in the family fall under the 'no-income' category, as do students. The group of welfare recipients includes persons who have never had paid employment and are not looking for work, such as some lone parents or some disabled individuals. But this category also contains individuals who are looking for jobs but have never worked before, such as school leavers, and contains those who have exhausted their unemployment benefit entitlement. Although it is clearly imperfect terminology, we do label the groups of individuals on welfare and on 'no income' as non-participants. Note that these individuals are identified in the income tax register data because they have entered the register at an earlier stage in their life.

We thus reduce the possible 15 sources of income to three distinct states: work, defined as only having income from wages or profits; unemployment, defined as having amongst the sources of income an unemployment benefit; and nonparticipation, defined as all other types of benefits, unspecified sources of income (such as alimony) or no-income. The main reason to make a distinction between unemployment and non-participation is not that the latter group does not search for jobs, but rather that it contains a higher percentage of individuals who do not search for jobs. To examine whether the distinction is empirically justified, we display the survival functions for the six possible transitions in Figure 3.

Several items stand out. We see that the transition rate from unemployment to work shows the familiar tendency to be high in the first few months and then to decrease over time. This can either be due to the fact that the most able individuals find jobs first or it may be due to a true time-effect.

Probably because the unemployed run out of entitlement, the transition rate from unemployment to non-participation increases over time. From non-participation to work we see somewhat lower transition rates to work. The transition rate from work into unemployment is lower, especially in the first year of employment, than the transition rate into non-participation. This may well be due to the fact that entitlement to benefits contained in non-participation is immediate, whereas it takes time in employment to build up any entitlement to unemployment benefits. There is hence some evidence of a systematic difference in the behaviour of the 
unemployed and the non-participants.

Another item standing out from these survival functions is that transitions show quite different duration dependencies, clearly indicating the need for a flexible baseline function as well as a possible need for a flexible heterogeneity distribution.

In order to see whether these transition rates differ by gender, we show the survival rates for women only, in Figure 4. Although the survival functions are not identical, the curvatures and levels of the survival rates for men and women together and for women only seem very similar for all possible transitions. Hence, in the ensuing analyses we allow for gender specific effects (also interacted with the number of children) in all transitions, but we do not perform separate analyses for women.

If we would want to use the whole population, we would have severe initialconditions problems: for those individuals already in the sample in 1989, it is not only unknown how long their current spell is in progress, but their whole labour market history is also unknown. Mainly for this reason, but also in order to avoid the problems that are involved if we analyse several different cohorts simultaneously, we use only the 4898 adults for whom we observe the time that they enter the income tax register, which is the moment they become active in the labour market. The summary statistics of these individuals in their first spells are then given in Table 1.

The results in this table show that most individuals live in a household with more than 1 individual, that average incomes in unemployment are rather higher than average incomes in work (though there is an obvious age-difference between workers and the unemployed), and that most of the labour-market entrants who live in households with children start in the work state. The table also shows that $71 \%$ of the entrants immediately has a job, probably straight out of school. The fact that there are some people who are observed to start in unemployment, even though they have no previous tax-record, is somewhat puzzling, because in the Dutch welfare system unemployment benefits are only given to individuals who have previously worked. The small number of entrants into unemployment have therefore probably had some previous incomes that were enough to qualify for unemployment benefits (such as odd jobs for work agencies), but not high enough to have previous tax records. After finishing school, they then claimed unemployment benefits. It is open for debate how we should view such individuals, but here we choose to see them as new entrants in unemployment.

The rough flows between the three states in the whole period are given in Table 2. On average, each individual experiences about 3 states in this period, 
and the flow between each state is considerable. Next we look at the distribution of these flows over individuals in Table 3. Here we can see that although a large number of individuals has only 1 or 2 spells, some 2249 individuals have more than two spells, which allows a careful look at the effect of previous outcomes (lengths of spells and incomes during these spells) on current transition rates.

Some problems with this data set that have to be mentioned: it is clear that the number of individual characteristics available is rather scant. In particular, there is no direct information available on education. As a proxy, we will use the age at which an individual enters the labour market. Also the information on incomes is restricted to the daily average income during a spell. Finally, entitlements to benefits are not known and cannot be computed accurately, for one because the number of hours worked is not known.

\section{Results}

\subsection{The model specification without income}

We consider a range of models, with gradually more persistence variables and increased flexibility of the unobserved heterogeneity distribution. First we show a basic specification in which we focus on the effect of the length of the cumulative time spent out of work in previous spells on the current hazard rates into employment. To allow for flexibility, we use four dummies to indicate whether this cumulate 'non-employment' (=unemployment + non-participation) has passed the threshold of 6 months, 1 year, 2 years, or 3 years. In this first specification, the unobserved heterogeneity terms have three possible values for each hazard rate and there are only three possible combinations (as in figure 1).

In the second specification we add more persistence variables, mainly to show that the coefficients of personal characteristics change substantially. This implies that the coefficients of personal characteristics in studies that ignore persistence effects will pick up part of the omitted persistence effect.

We mention that in the case with no income, virtually no likelihood improvement was made by adding extra flexibility to the unobserved heterogeneity distribution by means of allowing for 27 possible combinations. As we will see, when we consider income variable in the next section, added flexibility does add to the likelihood and is justified under Akaike's criterion.

In Table 4, we first show the results of a simple specification, where the heterogeneity distribution has three points of support, where there are no income variables included, and where the number of persistence variable is minimal. We 
postpone a discussion of the coefficients of individual characteristics until we reach the final specifications. We simply notice that these coefficients are quite different for the hazard rates for unemployment and non-participation, which shows another difference between these two states. Here, we are mostly interested in the persistence variables and whether these change substantially when we change the specification.

We can see here that the hazard from work generally increases when the previous duration of non-work is long, though there are marked jumps after 2 and 3 years. Hence, it is especially within the range of 0-2 years than an increasing duration of non-work increases hazard rates from employment. The hazard rates from unemployment do not relate significantly to the length of previous non-work in this specification.

Because the non-linearities are quite strong, we add more persistence variables, including a variable that indicates the length previously spent in work (which is meant to pick up a tenure effect) and a variable indicating the length of the previous spell without a job (which is supposed to tell us the importance of recent history); see Table 5. There are some major changes in the coefficients of the individual characteristics, including many sign reversals. Hence, in a specification without persistence variables the individual characteristics pick part of the effect of previous spells. As to the persistence effects themselves, we now see that the effects of previous non-work on the hazard rates from employment turn out to be more subtle: higher previous non-work duration decreases the hazard rate from work to unemployment and increases the hazard rate to non-participation. The effect of the cumulative previous non-work duration is almost opposite. This indicates that long previous non-work duration increases the hazard rate to unemployment if it is spread out over many previous non-work spells and decreases the hazard rate to unemployment if it is concentrated in the last non-work spell. The opposite goes for the hazard rates from employment to non-participation.

The hazard rates from unemployment to work are now significantly related to previous outcomes. There are some marked non-linearities however, which we will try to disentangle below.

The unobserved heterogeneity values show marked differences: the relative difference between the unobserved heterogeneity values is in the order of a factor 10 for most of the possible hazard rates and each possible combination has more than $15 \%$ probability mass. Both suggest quite a spread in unobserved heterogeneity terms. This in fact holds for the results in all specifications with three probability points. 


\subsection{Specifications with income}

Now, we add income variables (see Table 6 ). That is, we add income and variables summarising previous incomes (such as cumulative income and income in the previous spell). We immediately consider the final specification which includes 27 possible combinations of the individual heterogeneity terms (as in Figure 2).

Most of the found effects of individual characteristics are similar to those in Table 5: there is only one sign reversal and the absolute differences in the coefficients are also small. The difference in coefficients of the persistence variables is much bigger. The increase in the likelihood is sufficient to justify the inclusion of income variables.

The coefficients of the individual characteristics are not surprising. An exception is the insignificance of gender and the number of children on transition rates: though a higher number of children does, as expected, reduce transition rates out of non-participation (especially for women), the effects are not very significant or large. This signals that one of the main peculiarities of the Dutch labour market in previous decades, i.e., persistently low labour market participation levels of women (especially those with children), is a thing of the past for the new cohorts studied here.

The baseline hazards show some marked non-linearities, with perhaps the most striking the fact that baseline transition rates from work to non-participation are a lot higher after one year than they were just before the end of a year. Perhaps this reflects the fact that eligibility for wage related disability insurance benefits depends on the time that people have been employed prior to onset of the impairment (see for instance De Jong et al., 2008). That transition rates of unemployment to work are rather constant, whilst the transition rates into nonparticipation increase over time, is also not surprising because the possibility of claiming unemployment benefit disappears after a while. The seasonal effect shows that mobility is substantially lower during the colder months of the year (before April).

The longer the previous work duration, the lower the transition rates out of work. A higher cumulative work duration has the opposite effect. This means that a high cumulative work duration concentrated in the last work spell has much less effect on the exit rates out of employment than a high cumulative work duration spread over many work spells. Long un-interrupted spells of employment hence do not lead to a positive persistency for transition rates from work.

In general, the income persistencies are also clear: the higher previous incomes in non-employment, the lower the exit rates into work, and the higher the exit rates into unemployment. Because incomes in non-employment are strongly 
related to benefit levels, this signals a 'pull-effect' from higher benefits into unemployment. A high income during work increases future transition rates into work from the other states, which suggests that individuals pick up 'job-finding skills', such as contacts, during well-paid spells of employment. Also, those with a high income in previous job have a lower transition rate into non-participation. In comparison, the effects of cumulative income are small, though there is some indication that unemployed individuals who have earned a lot in the past, are more likely to go into non-participation than to work, perhaps representing a wealth effect for the demand for leisure.

The duration persistencies for time spent out of work are less clear. Previous non-work duration increases the chances of leaving employment and reduces the employment chances of those who are currently not working. On the other hand, the cumulative time spent out of work indicates opposite effects for exit rates out of work. Individuals who have been out of work for more than two years have lower exit rates out of employment, perhaps signaling that the experience of long times out of work may make workers more cautious not to lose their job. The net effect of longer previous spells of non-employment on transition rates to work is negative for those who have a long uninterrupted spell of nonemployment. Hence, it does seem that some skills are being lost during periods of non-employment. Apart from this negative effect of non-employment, the effect of longer spells without a job probably has a second negative persistency via the effect of long non-employment on future wages (see Table 9 in the Appendix for a basic income analysis). ${ }^{3}$

\subsection{Simulations}

Because the total impact of these persistencies are highly non-linear and, through the multiplicative structure of the MPH-model, depend on all the characteristics of all individuals, we need to look at simulations in which we turn some of the persistencies off if we want to get a feeling for the importance of the persistencies on labour participation rates.

Therefore we shall look at selected counterfactuals. In order to create counterfactuals, we must first simulate labour market histories under the assumption that the conditions of the model hold forever. Hence we have to calculate fic-

\footnotetext{
${ }^{3}$ Though the effect of the last non-employment spell on transition rates is positive, this effect is always smaller than that of the cumulative amount of time spent without a job. This suggests that individuals who often move between unemployment and non-participation during a long period of non-employment, lose less skills than individuals who are not mobile during a long period of non-employment.
} 
titious lives in which fictitious individuals change states stochastically and see their personal characteristics change just like individuals do in the sample. This will give us a reference base for the counterfactuals and will also give us some indication as to the ability of the model to explain actual participation rate, which provides a qualitative goodness-of-fit test.

The basis of the simulation is to take $M$ individuals with initial observed characteristics $x_{0}$, with unobserved heterogeneity $v_{0}$, with initial state $S_{0}$, and then to simulate entire labour market histories for these individuals, whereby the characteristics are updated annually to reflect the fact that some characteristics change over time (like age and the number of children).

There are four relevant issues that have to be dealt with in order to be able to do simulations:

1. The initial characteristics of the simulated population $x_{0}$ must be close to that of the actual population. We let the initial conditions of the simulated population be equal to the initial conditions of new entrants in the population, i.e. the younger cohorts. This means we start with an initial population in which the age of entry, gender, location, entry state, entry income and unobserved heterogeneity are chosen to coincide with that of new entrants. Each $M$ individuals thus consists of a random draw from the sample of new entrants. The simulated individual 'inherits' the starting characteristics of the assigned new entrant, as well as a random draw of the posterior Bayesian distribution of the unobserved heterogeneity $v$ of that new entrant random (this ex-post distribution is calculated by using the actual transition history of the entrant). The Appendix provides details. The choice to use the younger cohorts means the simulations are not meant to replicate the historical behaviour of the whole sample.

2. The changes in observable characteristics that affect transition rates must be close to those observed. This means we have to account for the fact that age, the number of children in the household and marital status change over time. For this we estimated simple probit transition models for the time-varying number of children and marital status. We estimated these probits on the entire sample of 65,000 individuals in the Income Panel data base.

3. Incomes during a spell must reflect personal characteristics and labour market history. For this we estimate log-incomes in two stages. In the first stage we predict whether an individual will have positive incomes in that spell 
based on his individual characteristics (probit). If the individual is assigned to have a positive income, he is given a random draw from a truncated log-normal income distribution with a mean determined by his observable characteristics and labour market history.

4. Transition intensities must reflect true transition intensities. For this we took the estimated hazard functions from Table 6 .

Hence we simulate individual labour market histories for 10,000 individuals by assigning them initial conditions that mimic those of new entrants and by then having them experience stochastically determined transitions, changes in personal characteristics and income changes according to the model predictions and additional simple estimations. An obvious weak point in this procedure is that the estimation of changes in personal characteristics and incomes is implicitly taken independent of the estimation of the MPH-models, basically because there are no good instruments to allow for endogeneities. This means we probably miss out on some important endogeneities which may hinder inferences.

We now look at two counterfactuals: in the first counterfactual we compute what would happen if there would be no effect from previous incomes in work and cumulative incomes. This means that we set the values of $\ln$ (Income prev. job), $\ln$ (Income prev. non-work) and $\ln$ (cum income) in Table 6 at zero for all transitions. In the third scenario we calculate what would happen if the duration of previous spells of non-employment would not have any effect. This implies setting the values of $\ln$ (cum. nw duration), the dummies for cum nw dur and $\ln$ (previous non-work dur) at zero for all transitions. The results are shown in Figure 5 in terms of labour market participation levels under the different scenarios. We add the averages of the participation rates of the sample of entrants for comparison.

Firstly we can see that there is a difference between the baseline simulation and the sample averages: the drop in participation rates and the subsequent increase is smaller for the simulations than in the sample. One reason for the divergence between the simulated participation rates and the actual ones is that the comparison is not entirely perfect: by construction, the actual participation rates in the sample are based on selective groups. Those starting aged 15 for instance in 1989 only reached the age of 23 in 1997. This means that the participation rate of individuals in the sample for those aged 24 will not contain anyone who started at age 15 , which is an obvious selection bias in the actual data. Hence, the composition of the sample participation rates does not reflect the composition of the simulation results, where everyone who enters is counted for all subsequent ages. The fact that the simulated participation rates are close to the entire population 
participation rate in this period (about 70\%) are encouraging in this sense.

Another important possible reason for this is that we treat the probability of finding a job when leaving school on a par with finding a job when being non-participant. In reality, the exit out of school may be endogenous to having a job outside school. If only those individuals leave school who have private information to believe they will quickly find a job, then the participation rate of those who left school will rise more quickly then our simulations would predict, giving rise to an underestimate for participation rates for the range of ages where individuals can leave school. Given that the simulated participation rates for older individuals is closer to the actual participation rate, this indeed could be one reason.

The general trends are the same though for the simulation and for the actual sample averages. The percentage of individuals in employment (=labour participation level) in the baseline simulation and in actuality is the lowest for individuals aged near 18, which is when a large glut of school leavers enters the labour market. Individuals entering the labour market before that age more often start in employment than the individuals who enter at 18. The simulation does replicate the initial decline and increase in participation rates for different ages and seems to produce a somewhat smoother line than the actual participation rates.

As we can see, the effect of omitting the income persistencies increases labour participation levels for individuals in the age range from 17 to 30 . In this range the negative persistencies from work income dominate and ignoring them hence results in lower participation rates. After this age range, the participation levels are almost the same without income persistencies. Looking at Table 6, the negative persistencies in question are that transition rates from employment are higher if previous incomes were higher and that transition rates to employment were lower when cumulative income was higher. The positive persistencies (higher transition rates into work with higher previous income) only outweigh these negative persistencies at higher ages.

For the persistencies from non-employment spells the results are clearer in the sense that labour market participation levels are a lot lower from about age 20 upwards when we ignore the length of non-employment. The net effect of previous spells of non-employment on current employment levels is hence positive. One positive persistence that can be observed from Table 6 is that longer cumulative spells (above 2 years) of non-employment decrease transition rates from work. This apparently outweighs the negative effect of longer periods of nonemployment on future transition rates from unemployment and non-participation 
to work.

\section{Simulations of duration and income inequality}

In the analysis of inequality, several studies have stressed the need to take account of the fact that cross-sectional inequality may grossly overstate the inequality in present values, if there is a large amount of mobility in the labour market (Flinn, 2002; Bowlus and Robin, 2004; Cohen, 1999). In the extreme case, when there is no discounting and individuals are homogeneous, life-time inequality may vanish for infinitely long lives whereas cross-sectional inequality may be substantial.

Bowlus and Robin (2004) and Cohen (1999) estimate or calibrate matching models and then use the estimates to calculate life-time inequality measures. Cohen (1999) finds that cross-sectional wage inequality is $60 \%$ higher in the US than in France, but total life-time earnings are only 15\% more unequal in the US than in France. Bowlus and Robin (2004) find that cross-sectional wages are about twice as unequal as life-time 'job values'.

Flinn simulates possible working experiences based on an estimated search model and also finds a substantial reduction in the amount of inequality when taking mobility into account. Most of the interest has hence been in wage inequality. Because this paper focuses on the proper estimation of transition rates however, we will confine our inequality analyses to inequality in non-employment duration.

Motivated by these preceding papers, we simulate here the inequality in cumulative non-employment duration for individuals who are 40 . We take 40 years of age as the cut-off point because that age is close to the maximum age range observed in the sample. We hence take the same simulation approach as above. To augment the same two counterfactuals as above, we also show here the amount of inequality that remains if we assume that there is no unobserved heterogeneity ${ }^{4}$. Because the preceding papers that look at inequality do not allow for unobserved heterogeneity, this puts our results apart from theirs and allows us to judge the importance of taking this factor into account.

In Figure 6 we show the cumulative time spent in unemployment under the baseline simulation and the three counterfactuals. Clearly, the amount of inequality is hardly affected by the persistencies. However, omitting unobserved heterogeneity significantly reduces the estimated amount of inequality. This is confirmed by Table 7, where we compute some inequality measures for the base-

\footnotetext{
${ }^{4}$ For each of the six possible transitions, each individual is then assigned the geometric mean of the three unobserved heterogeneity points.
} 
line, the cross-sectional distribution, and the counterfactuals.

First we may note that these inequality measure are much higher than those based on samples of workers or of households (such as those used by Bowlus and Robin, 2004). Hence our sample contains a lot of individuals with zero incomes or durations, which means that log-variation and 90/10 deciles cannot even be calculated for the cross-section. The only individuals with zero incomes live in households where someone else receives positive incomes or benefits, so these individual measures greatly overstate the amount of inequality at the household level.

Again we see that 'turning off' persistencies has little effect on inequalities. Turning off unobserved heterogeneity reduces inequality much more however: logduration inequality is about $50 \%$ lower without unobserved heterogeneity than with. Hence the dramatic drops that some authors find when they compare lifetime income inequality with cross-sectional inequality have to be taken with care if they do not allow for unobserved heterogeneity.

Inequality in cumulative duration does appear to be more than $50 \%$ lower than cross-sectional results, if we take the Gini-coefficient as a criterion. Hence this study also finds that cross-sectional inequality is a poor measure of lifetime inequality.

In Figure 7 we show the distribution of cumulative income for individuals aged 40 under the baseline model and with the persistencies and unobserved heterogeneity turned off. We only show the bottom $30 \%$ of the distribution because there is virtually no difference for the top $70 \%$. Here again we see that turning off the unobserved heterogeneity has the biggest influence on the distribution in the sense of reducing inequality. Turning employment persistence off increases inequality in the sense of increase the proportion of low-income individuals in the population, i.e. being in low-income jobs for a while reduces the prospects of getting higher income jobs later which increases inequality.

\subsection{Model variations}

In this sub-section we assess the importance of the flexibility of the unobserved heterogeneity distribution. We look at three different cases. The cases differ in two dimensions. They also differ in the amount of possible heterogeneity points for each transition exit, i.e., the number of mass-points of the marginal heterogeneity distribution $F_{j}^{x}$ of the transition from $x$ to $j$. The also differ in the restrictions on the possible combinations between the heterogeneity values of different states. 
1. Each $F_{j}^{x}$ has two mass-points. We only restrict the probability distribution of the exits from unemployment such that $P\left[\lambda_{j, i}^{u}=\lambda_{j, m}^{u}, \lambda_{k, i}^{u}=\lambda_{k, n}^{u}\right]=0$ iff $n \neq m$. Here, $\lambda_{j, i}^{u}$ denotes the particular heterogeneity value an individual $i$ has for the transition from $u$ to $j$. This leaves 12 heterogeneity points and 32 probability points to be estimated. A version in which there were no restrictions on the probability distribution did not converge.

2. Each $F_{j}^{x}$ has three mass-points and $P\left[\lambda_{j, i}^{x}=\lambda_{j, m}^{x}, \lambda_{k, i}^{y}=\lambda_{k, n}^{y}\right]=0$ iff $n \neq m$ for all $x$ and $y$. Hence there are then 18 heterogeneity points and only three probability points to be estimated.

3. Each $F_{j}^{x}$ has two mass-points and $P\left[\lambda_{j, i}^{x}=\lambda_{j, m}^{x}, \lambda_{k, i}^{y}=\lambda_{k, n}^{y}\right]=0$ iff $n \neq m$ for all $x$ and $y$. There are then 12 heterogeneity points and only two probability points to be estimated.

Table 8 shows the found heterogeneity points under each of these three specifications. In all cases, the biggest relative spread in the heterogeneity terms is found in the exits from work. If we use Akaike's information criterion, the ranking in terms of which model gives most information becomes: final model $\succ$ Spec. $2 \succ$ Spec. $3 \succ$ Spec. 1. The biggest increase in likelihood occurs when we switch from 2 to 3 heterogeneity points, whereas increased flexibility of the probability distribution delivers only marginal gains which barely make the final specification, with a 27 point probability distribution, better than specification 2 in which there are only 3 probability points. Hence, as a rule of thumb ' 3 is enough'.

\section{Conclusions}

Longer spells of well-paid employment increase future transition rates into work, indicating that these individuals pick up more skills in longer-lasting well-paid jobs. Combining this with the fact that the incomes during employment are also higher for individuals with longer previous employment spells, this provides evidence of a positive persistency of well-paid, long spells of employment.

The exit rates from non-employment (both unemployment and non-participation) to work decrease somewhat with longer previous spells of non-employment, and show marked drops if the previous spell of non-employment exceeds 2 years. This is in line with Omori (1997) and Blau (1994) who also find a negative effect of longer previous spells in non-employment on transition rates into employment. On the other hand, longer non-employment spells also decrease transition rates from employment to other states. This could be because individuals who take more time to search for work will on average end up in better-quality job matches, 
including jobs with a high degree of stability. Another explanation is that long non-employment spells are to some extent the result of childbearing episodes or periods spent in full-time education. Individuals who re-integrate after such an episode may have a strong preference for highly stable jobs.

Another robust finding is that higher previous incomes in non-employment increase the future transition rate from employment to unemployment and lower the exit rates into work. This hints at moral hazard.

In an attempt to assess the aggregate effects of these persistencies, we use the estimated models to simulate the consequences of switching off certain persistencies. These simulations reveal that the income persistencies from work do not have major aggregate effects except for individuals between 20 and 30 years of age, where these persistencies lead to higher levels of employment. The previous duration of non-employment increases employment levels, probably because individuals with long periods without a job have much lower transition rates from work. The implications of these simulations require a lot of caution because they require imputations of incomes and imputations of changes in personal characteristics. With these caveats in mind, the simulations predict that the contribution of persistencies to inequality is only modest. Without persistencies, the over-all inequality in the individual cumulative amount of time spent without work would only be slightly smaller than what is actually observed. Variation in observed and unobserved individual characteristics explains a much larger share of total inequality. However, one may argue that inequality due to persistences may be socially less acceptable than inequality due to acquired skills. After all, with persistencies, small exogenous random shocks to which individuals are exposed early on in their career create larger variations in outcomes across individuals much later in life. While the idiosyncratic shocks early in life may be hard to prevent, they lead to completely arbitrary inequality in wealth, and as such one may advocate redistributional policies to counterbalance their effects. A more modest policy would be to intervene in the causal chain created by the early shocks, and make a strong effort to mitigate the skill losses of individuals with very long spells in involuntary unemployment.

Our results imply that studies that restrict attention to persistencies across non-employment spells may miss out on causal effects running through other transition rates and incomes. The influence of those effects may then be picked up by observed factors in the model.

A limitation of our study is that it is partial, which means that we do not know whether the estimated effects are driven by supply factors or demand factors. This means that supply-side explanations for specific results should be made 
with caution.

An important omission in the analysis concerns the endogeneity of current incomes with respect to previous labour market outcomes and unobserved heterogeneity. Ad hoc analyses in the Appendix show significant relationships between incomes and previous labour market outcomes, but there are no instrumental variables available to take proper account of endogeneities. It seems very likely that the skills picked up in well-paid jobs that increase future exit rates into employment will also increase future earnings in all states, which probably increases exit rates into work. Similarly, the unobserved heterogeneity in the exit rates to work is bound to be related to incomes. As long as incomes are weakly endogenous, this problem does not affect the coefficients for the transition rates. However, the endogeneities do give rise to some caution concerning the validity of the model simulations. 


\section{Appendix}

\section{A1. Estimated unobserved heterogeneity distribution}

First, we list the estimated probability masses of the heterogeneity distribution in the final specification. By $P\left[\lambda_{1}^{e \rightarrow u}, \lambda_{1}^{e \rightarrow n}, \lambda_{1}^{u \rightarrow e}, \lambda_{1}^{u \rightarrow n}, \lambda_{1}^{n \rightarrow e}, \lambda_{1}^{n \rightarrow u}\right]$, we denote the joint probability that the individual's unobserved heterogeneity point for the transition from $e$ to $u$ is the first heterogeneity point, that the heterogeneity point for the transition from $e$ to $n$ is the first heterogeneity point, etc. For the 27 different probabilities, there holds (as in the tables, ${ }^{*}$ denotes significance at the $95 \%$ confidence level and $* *$ denotes significance at the $99 \%$ level):

$$
\begin{aligned}
& P\left[\lambda_{1}^{e \rightarrow u}, \lambda_{1}^{e \rightarrow n}, \lambda_{1}^{u \rightarrow e}, \lambda_{1}^{u \rightarrow n}, \lambda_{1}^{n \rightarrow e}, \lambda_{1}^{n \rightarrow u}\right] \approx 0.049 \\
& P\left[\lambda_{1}^{e \rightarrow u}, \lambda_{1}^{e \rightarrow n}, \lambda_{1}^{u \rightarrow e}, \lambda_{1}^{u \rightarrow n}, \lambda_{2}^{n \rightarrow e}, \lambda_{2}^{n \rightarrow u}\right] \approx 0.012 \\
& P\left[\lambda_{1}^{e \rightarrow u}, \lambda_{1}^{e \rightarrow n}, \lambda_{1}^{u \rightarrow e}, \lambda_{1}^{u \rightarrow n}, \lambda_{3}^{n \rightarrow e}, \lambda_{3}^{n \rightarrow u}\right] \approx 0.018 \\
& P\left[\lambda_{1}^{e \rightarrow u}, \lambda_{1}^{e \rightarrow n}, \lambda_{2}^{u \rightarrow e}, \lambda_{2}^{u \rightarrow n}, \lambda_{1}^{n \rightarrow e}, \lambda_{1}^{n \rightarrow u}\right] \approx 0.029 \\
& P\left[\lambda_{1}^{e \rightarrow u}, \lambda_{1}^{e \rightarrow n}, \lambda_{2}^{u \rightarrow e}, \lambda_{2}^{u \rightarrow n}, \lambda_{2}^{n \rightarrow e}, \lambda_{2}^{n \rightarrow u}\right] \approx 0.004 \\
& P\left[\lambda_{1}^{e \rightarrow u}, \lambda_{1}^{e \rightarrow n}, \lambda_{2}^{u \rightarrow e}, \lambda_{2}^{u \rightarrow n}, \lambda_{3}^{n \rightarrow e}, \lambda_{3}^{n \rightarrow u}\right] \approx 0.024 \\
& P\left[\lambda_{1}^{e \rightarrow u}, \lambda_{1}^{e \rightarrow n}, \lambda_{3}^{u \rightarrow e}, \lambda_{3}^{u \rightarrow n}, \lambda_{1}^{n \rightarrow e}, \lambda_{1}^{n \rightarrow u}\right] \approx 0.075 \\
& P\left[\lambda_{1}^{e \rightarrow u}, \lambda_{1}^{e \rightarrow n}, \lambda_{3}^{u \rightarrow e}, \lambda_{3}^{u \rightarrow n}, \lambda_{2}^{n \rightarrow e}, \lambda_{2}^{n \rightarrow u}\right] \approx 0.013 \\
& P\left[\lambda_{1}^{e \rightarrow u}, \lambda_{1}^{e \rightarrow n}, \lambda_{3}^{u \rightarrow e}, \lambda_{3}^{u \rightarrow n}, \lambda_{3}^{n \rightarrow e}, \lambda_{3}^{n \rightarrow u}\right] \approx 0.008 \\
& P\left[\lambda_{2}^{e \rightarrow u}, \lambda_{2}^{e \rightarrow n}, \lambda_{1}^{u \rightarrow e}, \lambda_{1}^{u \rightarrow n}, \lambda_{1}^{n \rightarrow e}, \lambda_{1}^{n \rightarrow u}\right] \approx 0.008 \\
& P\left[\lambda_{2}^{e \rightarrow u}, \lambda_{2}^{e \rightarrow n}, \lambda_{1}^{u \rightarrow e}, \lambda_{1}^{u \rightarrow n}, \lambda_{2}^{n \rightarrow e}, \lambda_{2}^{n \rightarrow u}\right] \approx 0.026 \\
& P\left[\lambda_{2}^{e \rightarrow u}, \lambda_{2}^{e \rightarrow n}, \lambda_{1}^{u \rightarrow e}, \lambda_{1}^{u \rightarrow n}, \lambda_{3}^{n \rightarrow e}, \lambda_{3}^{n \rightarrow u}\right] \approx 0.008 \\
& P\left[\lambda_{2}^{e \rightarrow u}, \lambda_{2}^{e \rightarrow n}, \lambda_{2}^{u \rightarrow e}, \lambda_{2}^{u \rightarrow n}, \lambda_{1}^{n \rightarrow e}, \lambda_{1}^{n \rightarrow u}\right] \approx 0.010 \\
& P\left[\lambda_{2}^{e \rightarrow u}, \lambda_{2}^{e \rightarrow n}, \lambda_{2}^{u \rightarrow e}, \lambda_{2}^{u \rightarrow n}, \lambda_{2}^{n \rightarrow e}, \lambda_{2}^{n \rightarrow u}\right] \approx 0.141 \\
& P\left[\lambda_{2}^{e \rightarrow u}, \lambda_{2}^{e \rightarrow n}, \lambda_{2}^{u \rightarrow e}, \lambda_{2}^{u \rightarrow n}, \lambda_{3}^{n \rightarrow e}, \lambda_{3}^{n \rightarrow u}\right] \approx 0.011 \\
& P\left[\lambda_{2}^{e \rightarrow u}, \lambda_{2}^{e \rightarrow n}, \lambda_{3}^{u \rightarrow e}, \lambda_{3}^{u \rightarrow n}, \lambda_{1}^{n \rightarrow e}, \lambda_{1}^{n \rightarrow u}\right] \approx 0.008 \\
& P\left[\lambda_{2}^{e \rightarrow u}, \lambda_{2}^{e \rightarrow n}, \lambda_{3}^{u \rightarrow e}, \lambda_{3}^{u \rightarrow n}, \lambda_{2}^{n \rightarrow e}, \lambda_{2}^{n \rightarrow u}\right] \approx 0.030 \\
& P\left[\lambda_{2}^{e \rightarrow u}, \lambda_{2}^{e \rightarrow n}, \lambda_{3}^{u \rightarrow e}, \lambda_{3}^{u \rightarrow n}, \lambda_{3}^{n \rightarrow e}, \lambda_{3}^{n \rightarrow u}\right] \approx 0.009 \\
& P\left[\lambda_{3}^{e \rightarrow u}, \lambda_{3}^{e \rightarrow n}, \lambda_{1}^{u \rightarrow e}, \lambda_{1}^{u \rightarrow n}, \lambda_{1}^{n \rightarrow e}, \lambda_{1}^{n \rightarrow u}\right] \approx 0.013 \\
& P\left[\lambda_{3}^{e \rightarrow u}, \lambda_{3}^{e \rightarrow n}, \lambda_{1}^{u \rightarrow e}, \lambda_{1}^{u \rightarrow n}, \lambda_{2}^{n \rightarrow e}, \lambda_{2}^{n \rightarrow u}\right] \approx 0.014 \\
& P\left[\lambda_{3}^{e \rightarrow u}, \lambda_{3}^{e \rightarrow n}, \lambda_{1}^{u \rightarrow e}, \lambda_{1}^{u \rightarrow n}, \lambda_{3}^{n \rightarrow e}, \lambda_{3}^{n \rightarrow u}\right] \approx 0.016 \\
& P\left[\lambda_{3}^{e \rightarrow u}, \lambda_{3}^{e \rightarrow n}, \lambda_{2}^{u \rightarrow e}, \lambda_{2}^{u \rightarrow n}, \lambda_{1}^{n \rightarrow e}, \lambda_{1}^{n \rightarrow u}\right] \approx 0.014 \\
& P\left[\lambda_{3}^{e \rightarrow u}, \lambda_{3}^{e \rightarrow n}, \lambda_{2}^{u \rightarrow e}, \lambda_{2}^{u \rightarrow n}, \lambda_{2}^{n \rightarrow e}, \lambda_{2}^{n \rightarrow u}\right] \approx 0.008 \\
& P\left[\lambda_{3}^{e \rightarrow u}, \lambda_{3}^{e \rightarrow n}, \lambda_{2}^{u \rightarrow e}, \lambda_{2}^{u \rightarrow n}, \lambda_{3}^{n \rightarrow e}, \lambda_{3}^{n \rightarrow u}\right] \approx 0.023 \\
& P\left[\lambda_{3}^{e \rightarrow u}, \lambda_{3}^{e \rightarrow n}, \lambda_{3}^{u \rightarrow e}, \lambda_{3}^{u \rightarrow n}, \lambda_{1}^{n \rightarrow e}, \lambda_{1}^{n \rightarrow u}\right] \approx 0.016 \\
& P\left[\lambda_{3}^{e \rightarrow u}, \lambda_{3}^{e \rightarrow n}, \lambda_{3}^{u \rightarrow e}, \lambda_{3}^{u \rightarrow n}, \lambda_{2}^{n \rightarrow e}, \lambda_{2}^{n \rightarrow u}\right] \approx 0.020 \\
& P\left[\lambda_{3}^{e \rightarrow u}, \lambda_{3}^{e \rightarrow n}, \lambda_{3}^{u \rightarrow e}, \lambda_{3}^{u \rightarrow n}, \lambda_{3}^{n \rightarrow e}, \lambda_{3}^{n \rightarrow u}\right] \approx 0.039
\end{aligned}
$$


For the marginal distributions of the heterogeneity distributions of the three states, this reduces to

$$
\begin{aligned}
& P\left[\lambda_{1}^{e \rightarrow u}, \lambda_{1}^{e \rightarrow n}\right] \approx 0.232^{* *} \\
& P\left[\lambda_{2}^{e \rightarrow u}, \lambda_{2}^{e \rightarrow n}\right] \approx 0.251^{* *} \\
& P\left[\lambda_{3}^{e \rightarrow u}, \lambda_{3}^{e \rightarrow n}\right] \approx 0.516^{* *} \\
& , \\
& P\left[\lambda_{1}^{u \rightarrow e}, \lambda_{1}^{u \rightarrow n}\right] \approx 0.155^{* *} \\
& P\left[\lambda_{2}^{u \rightarrow e}, \lambda_{2}^{u \rightarrow n}\right] \approx 0.267^{* *} \\
& P\left[\lambda_{3}^{u \rightarrow e}, \lambda_{3}^{u \rightarrow n}\right] \approx 0.588^{* *} \\
& , \text { and } \\
& P\left[\lambda_{1}^{n \rightarrow e}, \lambda_{1}^{n \rightarrow u}\right] \approx 0.223^{* *} \\
& P\left[\lambda_{2}^{n \rightarrow e}, \lambda_{2}^{n \rightarrow u}\right] \approx 0.269^{* *} \\
& P\left[\lambda_{3}^{n \rightarrow e}, \lambda_{3}^{n \rightarrow u}\right] \approx 0.508^{* *} .
\end{aligned}
$$

The main item of interest is that each marginal distribution is for each marginal probability distribution, there is at least $15 \%$ probability mass for any of the points, which indicates that the population is divided into more than just two groups.

\section{A2. Simulations}

In the simulations, the following steps were taken:

1. The joint distribution of age, gender, marital status, number of children, and living in a big city is set exactly equal to the distribution of new entrants in our sample. This was done by taking the initial characteristics at entry as the starting piece of information.

2. All individuals are assigned a vector of unobserved heterogeneity points according to the estimated probability distribution. This means that for each individual we draw a vector of unobserved heterogeneity points from a distribution that is obtained by construction a Bayesian estimate of the unobserved heterogeneity distribution of an individual based on his actual labour market history, with the estimated population densities as a prior distribution.

3. Considering all observed characteristics, an individual is assigned an income, by first specifying whether someone has a positive income or not (probit), and then, for those with positive incomes, to take a random draw of the estimated income distribution (log-normality with all characteristics 
as linear regressors, including previous lengths of employment and nonemployment spells (set at 0 for entrants)). This table is shown further on.

4. (January 1st each simulated year). All ages are increased by one year. Whether someone lives together and the number of children are re-assigned according to an estimated competing risk probit-model using all observations, using the characteristics of the previous state as variables.

5. Each day an individual's hazard rate to the two possible exits is computed (with the personal characteristics equal to the personal characteristics at the start of the spell). A random draws determine who makes an exit.

6. If someone changes states, he is re-assigned a new income.

7. If someone reaches the age of 45 , the simulation stops for that individual.

We mention that for the analysis of changes in household characteristics, we could use the whole data set, for which we knew of all individuals at the start of a new year what the household characteristics were at that moment.

Finally, Table 9 gives the results of the simple income model, in which we estimated $y_{i}^{k}=I_{\left(\alpha x_{i}+v_{i}^{k}\right)>0} \exp \left(\beta x_{i}+e_{i}^{k}\right)$, where $k$ denotes a particular state, $x_{i}$ a vector of characteristics at the start of a spell and where $v_{i}^{k}$ and $e_{i}^{k}$ are assumed to be independently normally distributed. Constant terms are not shown. In unemployment do all incomes exceed 0 . Hence we do not estimate $\alpha$ for unemployment. To improve efficiency and in order to allow us to simulate incomes for ages not contained in the panel of entrants, all the observations in the Income Panel are used, which changes the persistency variables we can use.

Of course, there are many endogenous variables in Table 9 (for instance the inclusion of previous incomes and previous work duration), and this hampers the interpretation. Given that these income regressions are only used for the simulations, where the main issue is to predict incomes as good as possible, this is not a major problem. Nevertheless, it is clear that persistencies may also run by way of the income values. 


\section{References}

Albaek, K., Larsen, A.H. (1993), 'Unemployment data, from surveys and administrative registers', in Bunzel, H., Jensen, P. and N. Westergård-Nielsen (eds.), Panel data and labour market dynamics, North Holland, pp. 123-47.

Arulampalam, W. (2002), 'State dependence in unemployment incidence: evidence for British men revisited', Working paper, IZA, Bonn.

Atkinson, A.B., Salverda, W. (2005), 'Top incomes In the Netherlands and the United Kingdom over the 20th century', Journal of the European Economic Association, vol. 3, pp. 883-913.

Blau, D.M. (1994), 'Labour force dynamics of older men', Econometrica, vol. 62, pp. $117-156$.

Bowlus, A.J., Robin, J-M, (2004), 'Twenty years of rising inequality in U.S. lifetime labour income values', Review of Economic Studies, vol. 71, pp. 709742.

Burgess, S, Propper, C., Rees, H., Shearer, A. (2003), 'The class of 1981: the effects of early career unemployment on subsequent unemployment experiences', Labour Economics, vol. 10, pp. 291-309.

Choi, H.J., Shin, D. (2002), 'Do past unemployment spells affect the duration of current unemployment?', Economics Letters, vol. 77, pp. 157-161.

Cohen, D. (1999), 'Welfare differentials across French and US labour markets', Working paper, CEPR, London.

D'Addio, A.C., Honoré, B.E. (2002), 'Duration dependence and timevarying variables in discrete time duration models', Working paper, University of Aarhus.

De Jong, P., Lindeboom, M., Van der Klaauw, B. (2008), 'Screening disability insurance applications', Working paper, IZA, Bonn.

De Koning, J., van Nes, P.J., van der Veen, C. (1998), Patronen van werkloosheid, Nederlands Economisch Instituut: VUGA, Den Haag.

Flinn, C.J. (2002), 'Labor market structure and welfare: a comparison of Italy and the US', Review of Economic Studies, vol. 69, pp. 611-645.

Frijters, P., Lindeboom, M., Van den Berg, G.J. (1999), 'Herhalingswerkloosheid: eindrapport', report for the ministry of Social Affairs, Staatsdrukkerij: Den Haag.

Gregg, P. (2001), 'The impact of youth unemployment on adult unemployment in the NCDS', Economic Journal, vol. 111, pp. 626-653. 
Heckman, J.J., Borjas, G. (1980), 'Does unemployment cause future unemployment?', Economica, pp. 247-283.

Lindbeck, A. (1995), 'Hazardous welfare state dynamics', American Economic Review, 85, Papers and Proceedings, 9-15.

Lindeboom, M. and G.J. van den Berg (1994), 'Heterogeneity in models for bivariate survival: the importance of the mixing distribution', Journal of the Royal Statistical Society, series B, vol. 56, pp. 49-60.

Ljungqvist, L., Sargent, T.J. (1998), 'The European unemployment dilemma', Journal of Political Economy, vol. 106(3), pp. 514-50.

Lynch, L.M. (1985), 'State dependence in youth unemployment: a lost generation?', Journal of Econometrics, pp. 71-84

Lynch, L.M. (1989), 'The youth labour market in the eighties: determinants of re-employment probabilities for young men and women', Review of Economic Studies, pp. 37-45.

Magnac, T. (2000), 'State dependence and unobserved heterogeneity in youth employment histories', Economic Journal, vol. 110, pp. 805837.

Manting, D., Bouman, A.M. (2006), 'Short- and long-term economic consequences of the dissolution of marital and consensual unions. the example of the Netherlands', European Sociological Review vol. 22, pp. 413-429.

Omori, Y. (1997), 'Stigma effects of nonemployment', Economic Enquiry, 35, pp. $394-416$

Phelps, E. (1972), Inflation policy and unemployment theory: the cost benefit approach to monetary planning. London, McMillan.

Piore, M.J. (1971), 'The dual labour market: theory and implications', in Problems in Political Economy: an urban perspective, Gordon, D. (ed.), Lexington Mass: Lexington books, pp. 93-97

Røed, K. (1997), 'Hysteresis in unemployment', Journal of Economic Surveys, 11(4), pp. 389-418.

Van den Berg. G.J. (2001). 'Duration models: specification, identification, and multiple durations.' In J. Heckman and E. Leamer (eds.), Handbook of Econometrics, Volume 5, North-Holland, Amsterdam.

Van Leeuwen, J., Pannekoek, J. (2002), 'To work oneself out of poverty: the Dutch experience 1989-96', Review of Income and Wealth vol. 48, pp. 127-40. 
Van Vuren, A.H., Van Vuuren, D.J. (2007), 'Financial incentives in disability insurance in the Netherlands', De Economist, vol. 155, pp. 73-98. 
Table 1: Summary statistics of individuals in the Income Panel data set at entry

\begin{tabular}{|c|c|c|c|c|}
\hline current state & Work & Unemployment & Non-participation & Total \\
\hline \multicolumn{5}{|l|}{ Variables } \\
\hline Age & 17.4 & 22.1 & 18.4 & 17.9 \\
\hline Female & 0.50 & 0.46 & 0.48 & 0.49 \\
\hline $\ln$ (taxable income per day in Dutch guilders) & 2.59 & 3.41 & 0.42 & 2.09 \\
\hline number of children in household & 1.13 & 0.46 & 0.83 & 1.03 \\
\hline Living together & 0.94 & 0.67 & 0.89 & 0.92 \\
\hline Living in one of the 4 major cities & 0.13 & 0.22 & 0.16 & 0.14 \\
\hline Individuals in percentages of whole & $71 \%$ & $4 \%$ & $25 \%$ & $100 \%$ \\
\hline
\end{tabular}

Table 2: The flows between the three labour market states for individuals in the Income Panel data set, in the period 1989-1997

\begin{tabular}{llllll}
\hline \multicolumn{1}{c}{ destination: } & work & unemployed & non-part. & right-censored & Total \\
\hline \hline Source: & & & & & \\
& & & & & \\
work & 0 & 1214 & 4206 & 3059 & 8479 \\
unemployed & 1162 & 0 & 210 & 202 & 1574 \\
non-participation & 3807 & 163 & 0 & 1637 & 5607 \\
Total & 4969 & 1377 & 4416 & 4898 & 15660 \\
\hline \hline
\end{tabular}


Table 3: The number of individuals having a certain number of spells in the Income Panel data set, in the period 1989-1997

\begin{tabular}{ll}
\hline & number of individuals \\
\hline \hline 1 spell & 1929 \\
2 spells & 719 \\
3 spells & 659 \\
4 spells & 336 \\
5 spells & 404 \\
6 spells & 180 \\
7 spells & 253 \\
8 spells & 121 \\
9 spells & 115 \\
10 or more spells & 181 \\
& \\
\hline \hline
\end{tabular}


Table 4: Results of the persistence model for Dutch labour market entrants: basic version without income.

\begin{tabular}{|c|c|c|c|c|c|c|}
\hline State & Work & & Unemployed & & Non-part & \\
\hline Variables $\quad \backslash$ & Unemployed & Non-part & Work & Non-part & Work & Unemployed \\
\hline \multicolumn{7}{|l|}{ Individual characteristics } \\
\hline Living together $(0=$ no, $1=$ yes $)$ & 0.06 & $-0.38^{* *}$ & $0.34^{* *}$ & -0.03 & $0.19^{* *}$ & -0.10 \\
\hline $\ln ($ age $)$ & $2.02^{* *}$ & $-2.43^{* *}$ & $-1.25^{* *}$ & -0.83 & $1.91^{* *}$ & $3.06^{* *}$ \\
\hline gender ( $1=$ female) & -0.09 & -0.00 & $-0.15^{* *}$ & 0.06 & $-0.12^{* *}$ & -0.10 \\
\hline \# kids & $-0.13^{* *}$ & 0.06 & -0.03 & -0.13 & $-0.14^{* *}$ & -0.12 \\
\hline \# kids*(gender) & 0.04 & -0.01 & $-0.19^{* *}$ & 0.11 & -0.00 & -0.23 \\
\hline Big city (1=yes) & 0.13 & -0.10 & $-0.40^{* *}$ & 0.17 & -0.09 & $0.40^{* *}$ \\
\hline age at entry ${ }^{*}$ work $^{a}$ & $-0.84^{*}$ & $1.34^{* *}$ & 0.39 & 1.42 & $-4.36^{* *}$ & $2.38^{*}$ \\
\hline age at entry*not-work & $-0.93^{*}$ & $1.47^{* *}$ & 0.24 & 1.41 & $-4.36^{* *}$ & 2.16 \\
\hline entry year of current spell & $-0.07^{* *}$ & $0.10^{* *}$ & $0.12^{* *}$ & $0.28^{* *}$ & -0.01 & $-0.16^{* *}$ \\
\hline \multicolumn{7}{|l|}{ Baseline } \\
\hline until day 32 & -8.62 & -5.58 & -5.53 & -8.63 & -5.83 & -8.20 \\
\hline day $33-63$ & $-8.83^{* *}$ & $-6.31^{* *}$ & $-5.62^{* *}$ & $-8.35^{* *}$ & $-5.98^{* *}$ & $-9.24^{* *}$ \\
\hline day 64-155 & $-8.50^{* *}$ & $-6.38^{* *}$ & $-5.61^{* *}$ & $-7.59 * *$ & $-5.54^{* *}$ & $-9.17^{* *}$ \\
\hline day 155-366 & $-9.10^{* *}$ & $-6.61^{* *}$ & $-6.30^{* *}$ & $-7.27^{* *}$ & $-5.68^{* *}$ & $-9.25^{* *}$ \\
\hline after day 365 & $-9.54^{* *}$ & $-5.07^{* *}$ & $-5.69^{* *}$ & $-7.73^{* *}$ & $-5.23^{* *}$ & $-8.82^{* *}$ \\
\hline \multicolumn{7}{|l|}{ Season } \\
\hline After April 1 & -0.11 & $1.05^{* *}$ & 0.07 & $0.64^{* *}$ & $0.78^{* *}$ & $0.45^{*}$ \\
\hline \multicolumn{7}{|l|}{ Persistence effects } \\
\hline cum. non-work dur ${ }^{b}>6$ mo. & $0.81^{* *}$ & $0.30^{* *}$ & 0.01 & 0.17 & $-0.25^{* *}$ & 0.36 \\
\hline cum nw dur $>1$ yr & 0.05 & $0.11^{*}$ & 0.10 & -0.11 & $0.22^{* *}$ & 0.35 \\
\hline cum nw dur $>2 \mathrm{yr}$ & -0.15 & $-0.55^{* *}$ & -0.13 & -0.03 & 0.05 & 0.18 \\
\hline cum nw dur $>3 \mathrm{yr}$ & -0.11 & -0.01 & 0.17 & 0.08 & $-0.15^{*}$ & -0.36 \\
\hline \multicolumn{7}{|l|}{ Heterogeneity points } \\
\hline point $1(\mathrm{P}=0.18)$ & $0.32^{* *}$ & $0.94^{* *}$ & $1.82^{* *}$ & $1.02^{* *}$ & $0.30^{* *}$ & $0.09 * *$ \\
\hline point $2(\mathrm{P}=0.26)$ & $0.24^{* *}$ & $3.01^{* *}$ & $1.02^{* *}$ & $0.89^{* *}$ & $0.85^{* *}$ & $1.04^{* *}$ \\
\hline point $3(\mathrm{P}=0.56)$ & $0.05^{* *}$ & $0.70^{* *}$ & $1.04^{* *}$ & $0.69^{* *}$ & $0.13^{* *}$ & $0.67 * *$ \\
\hline Average Log likelihood & & & -17.697 & & & \\
\hline Percentages of total \# spells & $50 \%$ & & $18 \%$ & & $34 \%$ & \\
\hline
\end{tabular}

${ }^{a}$ Interaction of age at entry and whether the first state was in work, ${ }^{b}$ Total duration without a job,

$*$ signif at 5\%, ** signif. at $1 \%$. nw=non-work. Observed individual characteristics are normalised to mean zero. 
Table 5: Results of the persistence model for Dutch labour market entrants: version without income but with extended persistence variables.

\begin{tabular}{|c|c|c|c|c|c|c|}
\hline State & Work & & Unemployed & & Non-part & \\
\hline exit-state & Unemployed & Non-part & Work & Non-part & Work & Unemployed \\
\hline \multicolumn{7}{|l|}{ Individual characteristics } \\
\hline Living together $(0=$ no, $1=$ yes $)$ & -0.02 & $-0.32^{* *}$ & $0.32^{* *}$ & -0.03 & $0.14^{* *}$ & -0.6 \\
\hline $\ln ($ age $)$ & -0.10 & $-2.65^{* *}$ & $-2.17^{* *}$ & -0.42 & $0.70^{*}$ & $2.94^{*}$ \\
\hline gender ( $1=$ female $)$ & -0.06 & -0.04 & $-0.16^{* *}$ & 0.03 & $-0.08^{*}$ & -0.01 \\
\hline \# kids & $-0.09^{*}$ & $0.10^{* *}$ & -0.01 & -0.14 & $-0.13^{* *}$ & -0.04 \\
\hline \# kids*(gender) & 0.03 & -0.02 & $-0.17^{*}$ & 0.12 & 0.01 & -0.29 \\
\hline Big city (1=yes) & 0.13 & -0.10 & $-0.37^{* *}$ & 0.13 & -0.06 & $0.48^{* *}$ \\
\hline age at entry ${ }^{*}$ work $^{a}$ & 0.83 & $1.48^{* *}$ & $1.24^{* *}$ & 1.13 & $-3.31^{* *}$ & 2.53 \\
\hline age at entry*not-work & 0.79 & $1.52^{* *}$ & $1.29 * *$ & 1.13 & $-3.18^{* *}$ & 2.52 \\
\hline entry year of current spell & $-0.11^{* *}$ & $0.10^{* *}$ & $0.08^{* *}$ & $0.26^{* *}$ & -0.01 & -0.21 \\
\hline \multicolumn{7}{|l|}{ Baseline } \\
\hline until day 32 & -8.62 & -5.58 & -5.53 & -8.63 & -5.83 & -8.20 \\
\hline day $33-63$ & $-8.76^{* *}$ & $-6.27^{* *}$ & $-5.55^{* *}$ & $-8.42^{* *}$ & $-5.98^{* *}$ & $-8.96^{* *}$ \\
\hline day 64-155 & $-8.44^{* *}$ & $-6.29^{* *}$ & $-5.52^{* *}$ & $-7.63^{* *}$ & $-5.59 * *$ & $-9.04^{* *}$ \\
\hline day 155-366 & $-8.98^{* *}$ & $-6.48^{* *}$ & $-6.13^{* *}$ & $-7.30^{* *}$ & $-5.85^{* *}$ & $-9.23^{* *}$ \\
\hline after day 365 & $-9.40^{* *}$ & $-4.96^{* *}$ & $-5.49 * *$ & $-7.83^{* *}$ & $-5.40^{* *}$ & $-8.45^{* *}$ \\
\hline \multicolumn{7}{|l|}{ Season } \\
\hline After April 1 & -0.08 & $1.08^{* *}$ & 0.15 & $0.63^{* *}$ & $0.72^{* *}$ & $0.70^{* *}$ \\
\hline \multicolumn{7}{|l|}{ Persistence effects } \\
\hline $\ln (\text { cum. nw duration })^{b}$ & $0.31^{* *}$ & $-0.14^{* *}$ & $0.14^{* *}$ & 0.08 & $0.11^{* *}$ & $0.25^{*}$ \\
\hline cum. nw dur $>6$ mo. & 0.07 & -0.11 & -0.15 & -0.03 & $-0.21^{* *}$ & 0.16 \\
\hline cum nw dur $>1 \mathrm{yr}$ & -0.08 & 0.01 & 0.01 & -0.21 & 0.15 & 0.34 \\
\hline cum nw dur $>2$ yr & $-0.25^{*}$ & $-0.47^{* *}$ & -0.16 & -0.08 & -0.02 & 0.04 \\
\hline cum nw dur $>3 \mathrm{yr}$ & -0.14 & 0.05 & 0.16 & 0.04 & $-0.21^{* *}$ & -0.41 \\
\hline $\ln ($ cum. work dur) & 0.05 & $0.14^{* *}$ & $0.10^{* *}$ & 0.03 & -0.03 & 0.09 \\
\hline $\ln ($ previous non-work dur) & $-0.20^{* *}$ & $0.32^{* *}$ & $-0.11^{* *}$ & -0.04 & $-0.12^{* *}$ & $-0.24^{*}$ \\
\hline $\ln ($ prev. work dur) & 0.05 & $-0.12^{* *}$ & $0.07^{*}$ & -0.04 & $0.11^{* *}$ & 0.06 \\
\hline \multicolumn{7}{|l|}{ Heterogeneity points } \\
\hline point $1(\mathrm{P}=0.23)$ & 0.74 & 0.61 & 0.85 & 1.75 & 0.40 & 0.12 \\
\hline point $2(\mathrm{P}=0.21)$ & 0.15 & 0.14 & 0.26 & 0.94 & 0.84 & 0.67 \\
\hline point $3(\mathrm{P}=0.56)$ & 2.68 & 0.05 & 0.71 & 0.71 & 0.17 & 0.39 \\
\hline Average Log likelihood & & & -17.649 & & & \\
\hline Percentages of total \# spells & $50 \%$ & & $18 \%$ & & $34 \%$ & \\
\hline
\end{tabular}

\footnotetext{
${ }^{a}$ Interaction of age at entry and whether the first state was in work

${ }^{b}$ Total duration without a job. * signif at $5 \%,{ }^{* *}$ signif $_{33}$ at $1 \%$
} 
Table 6: Results of the persistence model with income and 27 possible unobserved heterogeneity combinations for Dutch labour market entrants.

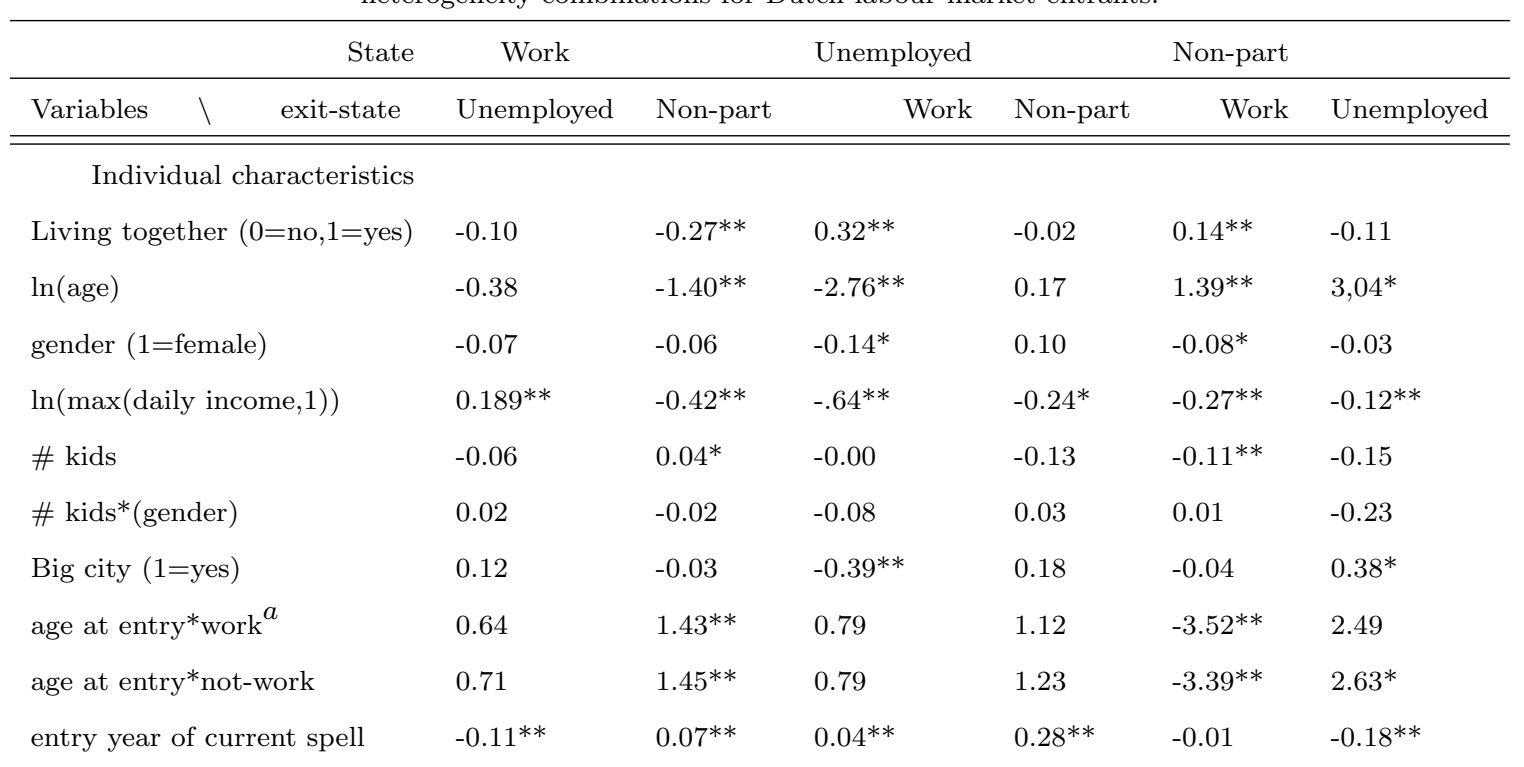

Baseline

until day 32
day $33-63$
day $64-155$
day $155-366$
after day 365
Season

After April 1

$\begin{array}{llllll}-8.62 & -5.58 & -5.53 & -8.63 & -5.83 & -8.20 \\ -8.73^{* *} & -6.32^{* *} & -5.53^{* *} & -8.32^{* *} & -5.97^{* *} & -9.17^{* *} \\ -8.28^{* *} & -6.34^{* *} & -5.42^{* *} & -7.58^{* *} & -5.55^{* *} & -9.12^{* *} \\ -8.52^{* *} & -6.50^{* *} & -5.86^{* *} & -7.29^{* *} & -5.79^{* *} & -9.02^{* *} \\ -8.84^{* *} & -4.96^{* *} & -5.30^{* *} & -7.81^{* *} & -5.34^{* *} & -8.41^{* *}\end{array}$

Season

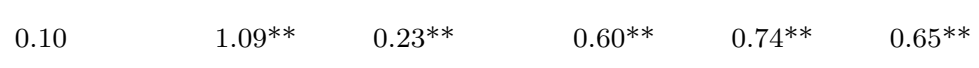

Persistence effects

\begin{tabular}{|c|c|c|c|c|c|c|}
\hline $\ln (\text { cum. nw duration })^{b}$ & -0.04 & -0.02 & $0.23^{* *}$ & 0.13 & $0.06^{*}$ & -0.13 \\
\hline cum. nw dur $>6$ mo. & 0.12 & -0.06 & -0.11 & -0.00 & $-0.18^{* *}$ & 0.25 \\
\hline cum nw dur $>1$ yr & -0.06 & 0.10 & -0.03 & -0.20 & $0.12^{*}$ & 0.16 \\
\hline cum nw dur $>2 \mathrm{yr}$ & $-0.50 * *$ & $-0.36^{* *}$ & -0.19 & -0.09 & -0.01 & 0.11 \\
\hline cum nw dur $>3 \mathrm{yr}$ & -0.08 & 0.03 & 0.17 & 0.03 & $-0.16^{*}$ & -0.34 \\
\hline $\ln ($ cum. work dur $)$ & $0.23^{* *}$ & $0.12^{* *}$ & 0.05 & -0.01 & 0.02 & $0.29^{* *}$ \\
\hline $\ln ($ previous non-work dur) & $0.09^{*}$ & $0.18^{* *}$ & $-0.18^{* *}$ & -0.07 & $-0.09 * *$ & 0.02 \\
\hline $\ln$ (prev. work dur) & $-0.13^{* *}$ & -0.04 & $0.19^{* *}$ & 0.02 & $0.06^{* *}$ & -0.05 \\
\hline $\ln$ (Income prev. job) & 0.05 & $-0.05^{* *}$ & $0.12^{* *}$ & -0.15 & $0.08^{* *}$ & 0.09 \\
\hline $\ln ($ Income prev. non-work) & $0.15^{* *}$ & $-0.42^{* *}$ & $-0.11^{* *}$ & -0.06 & $-0.08^{* *}$ & $0.19^{* *}$ \\
\hline $\ln ($ cum income $)$ & -0.03 & 0.02 & $-0.10^{*}$ & 0.01 & 0.01 & -0.04 \\
\hline
\end{tabular}

Heterogeneity points

\begin{tabular}{|c|c|c|c|c|c|c|}
\hline point 1 & $2.59^{* *}$ & $0.60^{* *}$ & $0.25^{* *}$ & $1.26^{* *}$ & $0.19^{* *}$ & $0.37^{* *}$ \\
\hline point 2 & $0.21^{* *}$ & $0.22^{* *}$ & $0.10^{* *}$ & $1.35^{* *}$ & $0.44^{* *}$ & $0.52^{* *}$ \\
\hline point 3 & $0.45^{* *}$ & $0.13^{* *}$ & $0.39 * *$ & $0.96^{* *}$ & $0.13^{* *}$ & $0.05 * *$ \\
\hline
\end{tabular}

Average Log likelihood

Percentages of total \# spells

$50 \%$

$18 \%$

$34 \%$

${ }^{a}$ Interaction of age at entry and whether the first state was in work

${ }^{b}$ Total duration without a job. * signif at $5 \%, * *$ signif. at $1 \%$ 
Table 7: Estimated measures of cumulative non-employment duration inequality of individuals aged 40

\begin{tabular}{llllll}
\hline & $\begin{array}{l}\text { Cross-section } \\
\text { at age } 40\end{array}$ & $\begin{array}{l}\text { Baseline } \\
\text { simulation }\end{array}$ & $\begin{array}{l}\text { no-income } \\
\text { persistencies }\end{array}$ & $\begin{array}{l}\text { no non-empl. } \\
\text { persistencies }\end{array}$ & $\begin{array}{l}\text { no unobs. } \\
\text { heterogeneity }\end{array}$ \\
\hline \hline 90/10 non-emp. dur. decile & $\infty$ & 8.5 & 8.1 & 8.9 & 5.4 \\
var(ln(cum. non-empl. dur.) & $\infty$ & 1.33 & 1.20 & 1.06 & 0.69 \\
Gini-coefficient non-empl. dur & 0.46 & 0.20 & 0.19 & 0.19 & 0.17 \\
\hline \hline
\end{tabular}

Table 8: Heterogeneity points found under different specifications with income

\begin{tabular}{lllllllll}
\hline & $\begin{array}{c}\text { Work } \\
\text { unem. }\end{array}$ & other & $\begin{array}{c}\text { Unemployment } \\
\text { work }\end{array}$ & $\begin{array}{c}\text { Other } \\
\text { other }\end{array}$ & work & unem. & $\begin{array}{c}\text { Average } \\
\text { Log-lik }\end{array}$ & $\begin{array}{l}\text { Number } \\
\text { of params }\end{array}$ \\
\hline \hline Specif. 1 & & & & & & & -17.5280 & 193 \\
point 1 & 2.32 & 0.46 & 0.28 & 0.80 & 0.27 & 0.20 & & \\
point 2 & 0.25 & 0.10 & 0.25 & 0.66 & 0.30 & 0.18 & & \\
& & & & & & & & \\
Specif. 2 & & & & & & & -17.5149 & 170 \\
point 1 & 2.41 & 0.60 & 0.30 & 0.82 & 0.23 & 0.40 & & \\
point 2 & 0.23 & 0.22 & 0.13 & 0.94 & 0.55 & 0.52 & & \\
point 3 & 0.45 & 0.12 & 0.46 & 0.85 & 0.16 & 0.06 & & \\
Specif. 3 & & & & & & & & \\
point 1 & 2.25 & 0.61 & 0.15 & 0.70 & 0.20 & 0.33 & & \\
point 2 & 0.38 & 0.17 & 0.26 & 0.78 & 0.34 & 0.19 & & \\
& & & & & & & & \\
Final spec & & & & & & & -17.5100 & \\
point 1 & 2.59 & 0.60 & 0.25 & 1.26 & 0.19 & 0.37 & & \\
point 2 & 0.21 & 0.22 & 0.10 & 1.35 & 0.44 & 0.52 & & \\
point 3 & 0.45 & 0.13 & 0.39 & 0.96 & 0.13 & 0.05 & & \\
\hline \hline
\end{tabular}


Table 9: Results of the income model

\begin{tabular}{|c|c|c|c|c|c|}
\hline \multirow[t]{2}{*}{ State } & \multicolumn{2}{|c|}{ Work } & Unemployed & \multicolumn{2}{|c|}{ Non-participation } \\
\hline & $\alpha$ & $\beta$ & $\beta$ & $\alpha$ & $\beta$ \\
\hline Living together $(0=$ no, $1=$ yes $)$ & -0.07 & $0.22^{* *}$ & -0.04 & $0.18^{* *}$ & -0.08 \\
\hline $\ln ($ age $)$ & 0.92 & $2.93^{* *}$ & $2.07^{* *}$ & $-2.02^{* *}$ & $2.10^{* *}$ \\
\hline gender $(1=$ female $)$ & -0.04 & $-0.11^{* *}$ & -0.04 & -0.06 & $-0.16^{*}$ \\
\hline \# kids & 0.013 & $-0.11^{* *}$ & -0.04 & $-0.06^{*}$ & $-0.14^{* *}$ \\
\hline \# kids*(gender) & 0.13 & -0.01 & $-0.06^{*}$ & 0.05 & $0.15^{*}$ \\
\hline Big city $(1=$ yes $)$ & -0.06 & 0.03 & -0.01 & $-0.12^{*}$ & 0.05 \\
\hline age at entry* ${ }^{*}$ work $^{a}$ & 0.51 & -0.12 & $-0.80 * *$ & 0.54 & -0.25 \\
\hline age at entry*not-work & 0.48 & -0.16 & $-0.78^{* *}$ & 0.48 & -0.22 \\
\hline $\ln (\text { cum. nw duration })^{b}$ & -0.13 & -0.01 & $-0.03^{*}$ & $0.16^{* *}$ & -0.04 \\
\hline cum. nw dur $>6$ mo. & 0.34 & -0.01 & -0.01 & -0.10 & 0.01 \\
\hline cum nw dur $>1 \mathrm{yr}$ & 0.10 & -0.02 & 0.04 & 0.07 & 0.10 \\
\hline cum nw dur $>2 \mathrm{yr}$ & 0.20 & -0.01 & -0.07 & -0.11 & -0.04 \\
\hline cum nw dur $>3 \mathrm{yr}$ & -0.05 & -0.01 & -0.03 & -0.11 & 0.06 \\
\hline $\ln ($ cum. work dur $)$ & 0.04 & -0.00 & 0.01 & $-0.13^{* *}$ & $0.15^{* *}$ \\
\hline $\ln ($ previous non-work dur) & -0.01 & 0.01 & 0.01 & $-0.08^{*}$ & -0.05 \\
\hline $\ln ($ prev. work dur) & -0.08 & -0.02 & $-0.07 * *$ & -0.01 & $-0.18^{* *}$ \\
\hline $\ln ($ Income prev. job) & -0.07 & $0.07^{* *}$ & $0.14^{* *}$ & $-0.05^{*}$ & $0.23^{* *}$ \\
\hline $\ln ($ Income prev. non-work $)$ & -0.03 & $0.13^{* *}$ & $0.04^{* *}$ & $-0.28^{* *}$ & $0.08^{* *}$ \\
\hline $\ln ($ cum income $)$ & $0.08^{* *}$ & -0.005 & $0.04^{* *}$ & 0.03 & $0.07^{*}$ \\
\hline first spell? (1=yes) & 0.01 & -0.09 & 0.26 & $-1.02^{* *}$ & 0.53 \\
\hline day of entry & $0.002^{* *}$ & 0.000 & $0.0002^{*}$ & $0.003^{* *}$ & $-0.0007^{* *}$ \\
\hline year of entry & $-0.68^{* *}$ & $-0.07^{*}$ & $-0.09^{* *}$ & $-1.03^{* *}$ & $0.25^{* *}$ \\
\hline Log likelihood / $\mathrm{R}^{2}$ & -547.35 & 0.32 & 0.25 & -1979.1 & 0.29 \\
\hline $\mathrm{N}$ & 8479 & 8368 & 1585 & 5611 & 832 \\
\hline
\end{tabular}

${ }^{a}$ Interaction of age at entry and whether the first state was in work

$b$ Total duration without a job. $*$ signif at $5 \%, * *$ signif. at $1 \%$ 


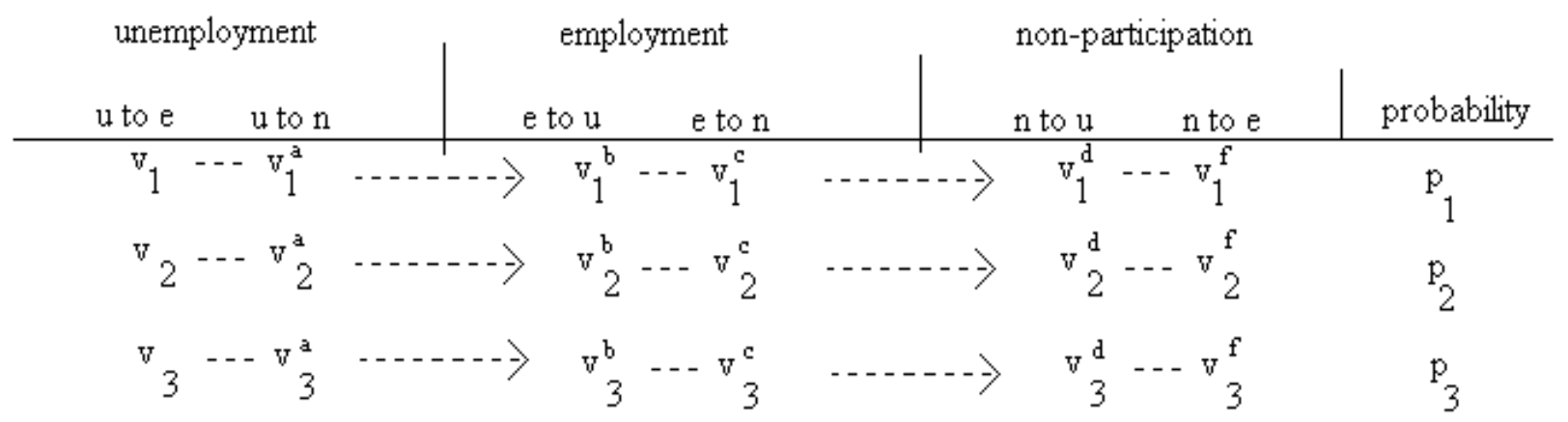

Restricted heterogeneity distribution: 3 probability points

Figure 1: 3-point heterogeneity distribution

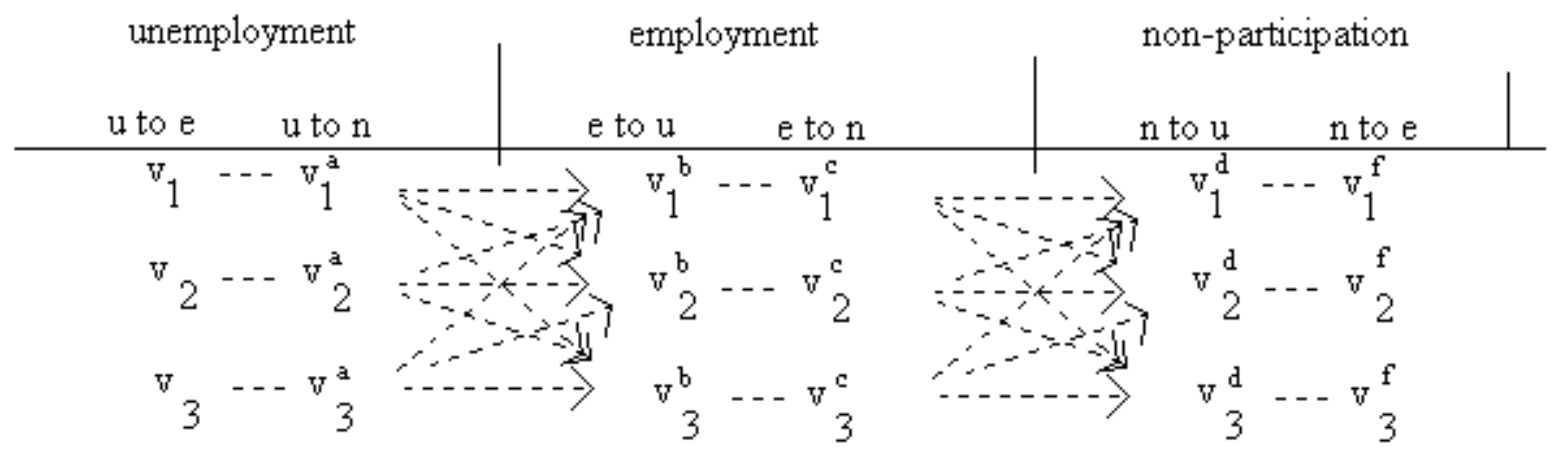

Less restricted heterogeneity: $3 * 3 * 3$ probability points

Figure 2: 27-point heterogeneity distribution 

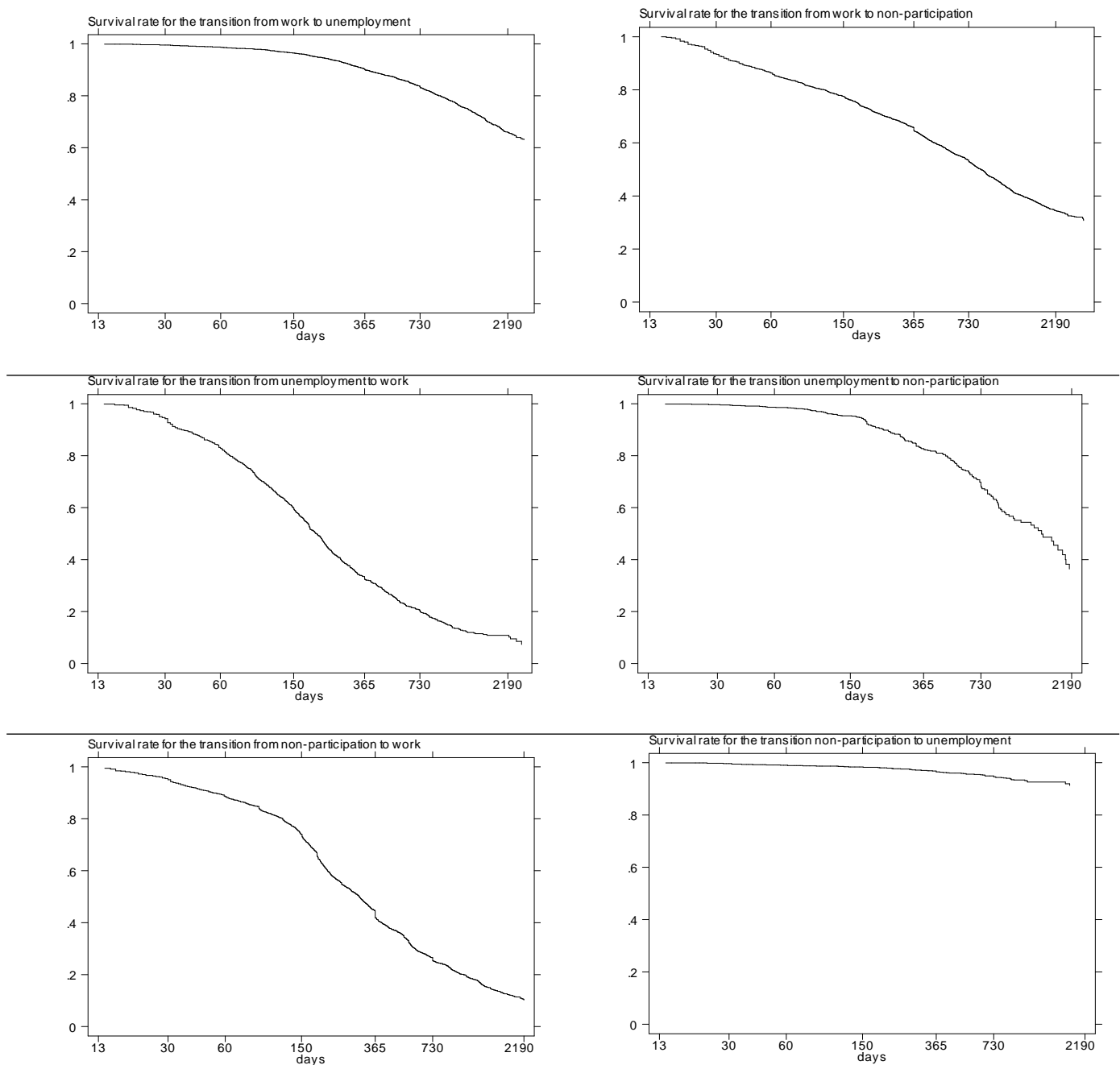

Figure 3a-3f: survival rates for males and females combined. 
Survival rate females from work to unemployment

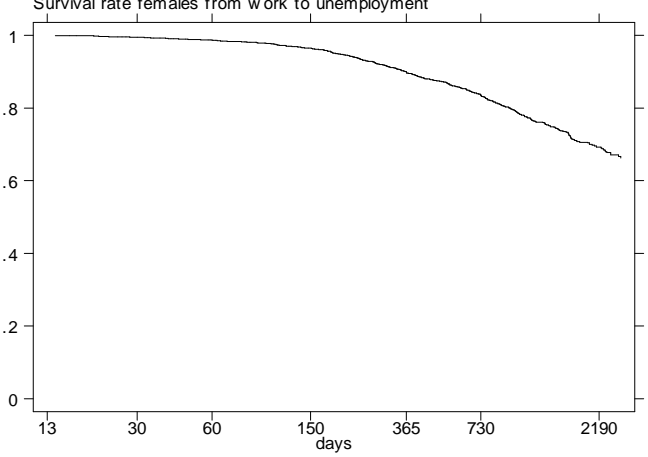

Survival rate females work to non-participation
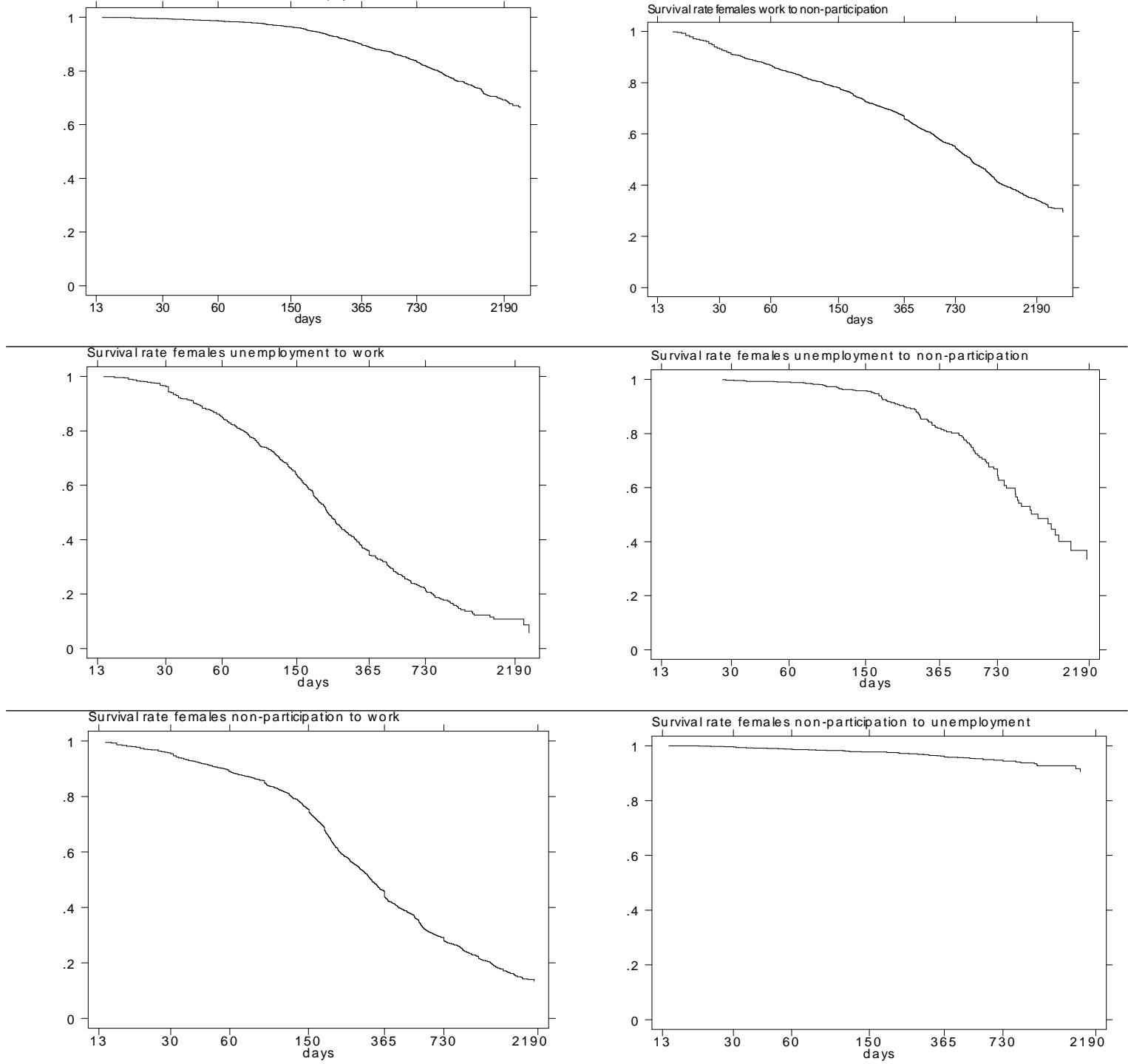

Figure 4a-4f: Survival rates for females. 


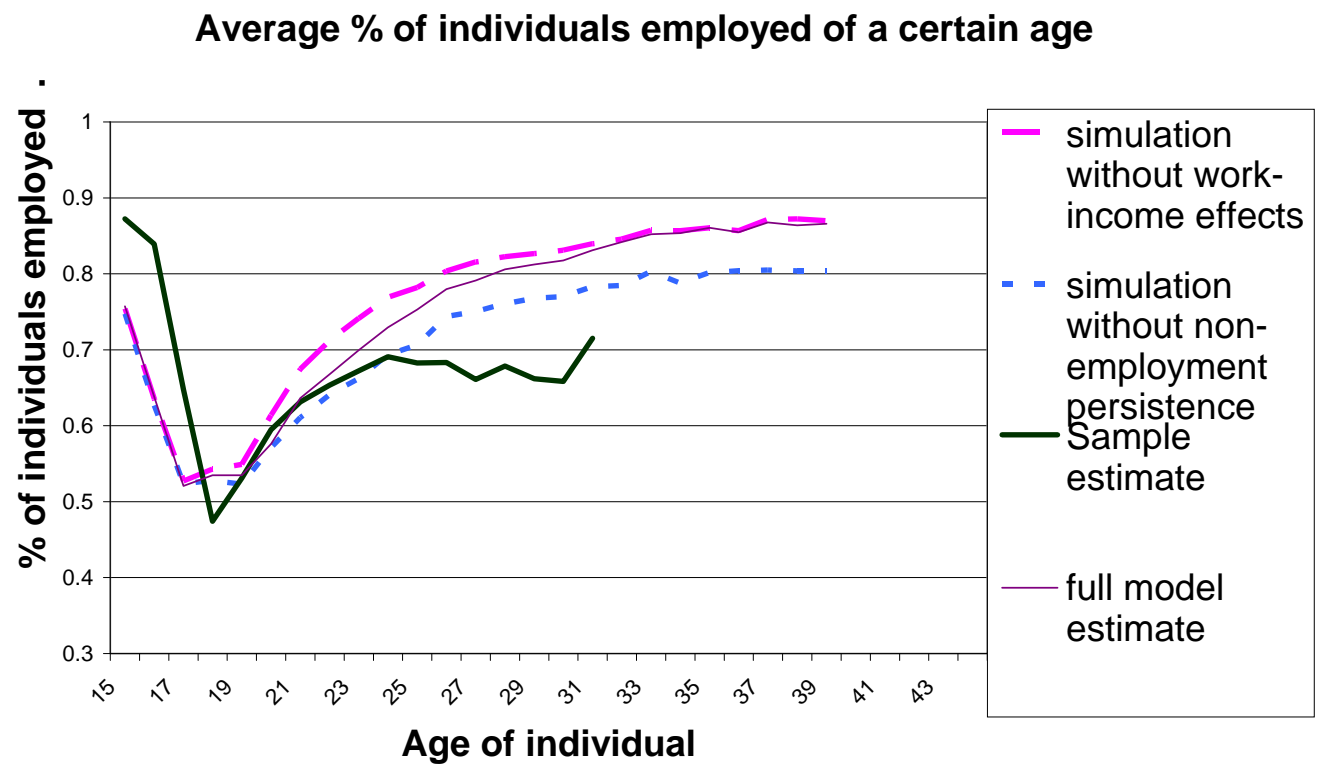

Figure 5.

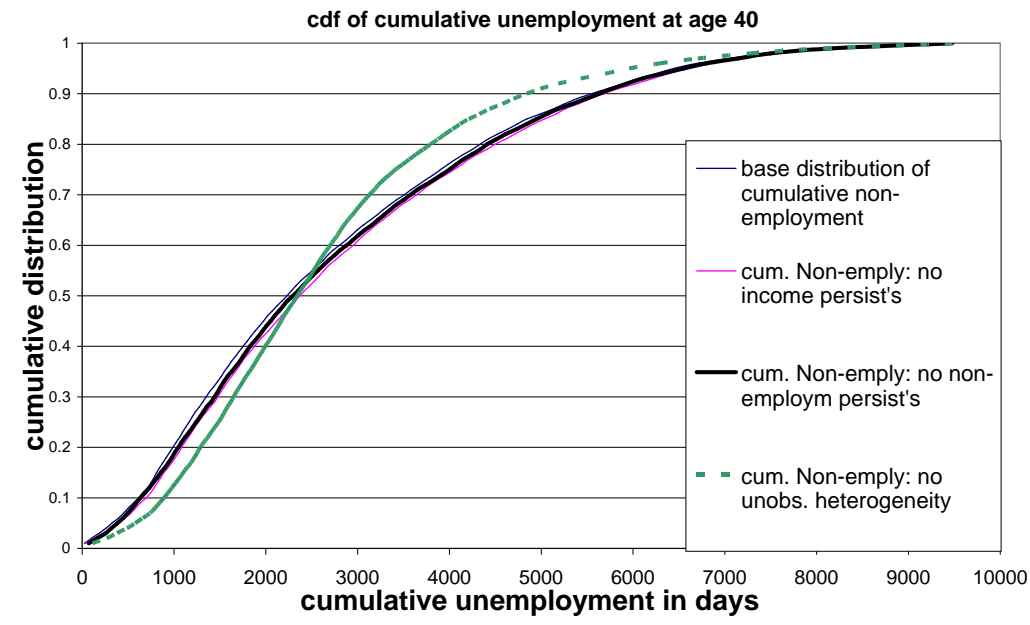

Figure 6 . 
cdf of cumulative incomes

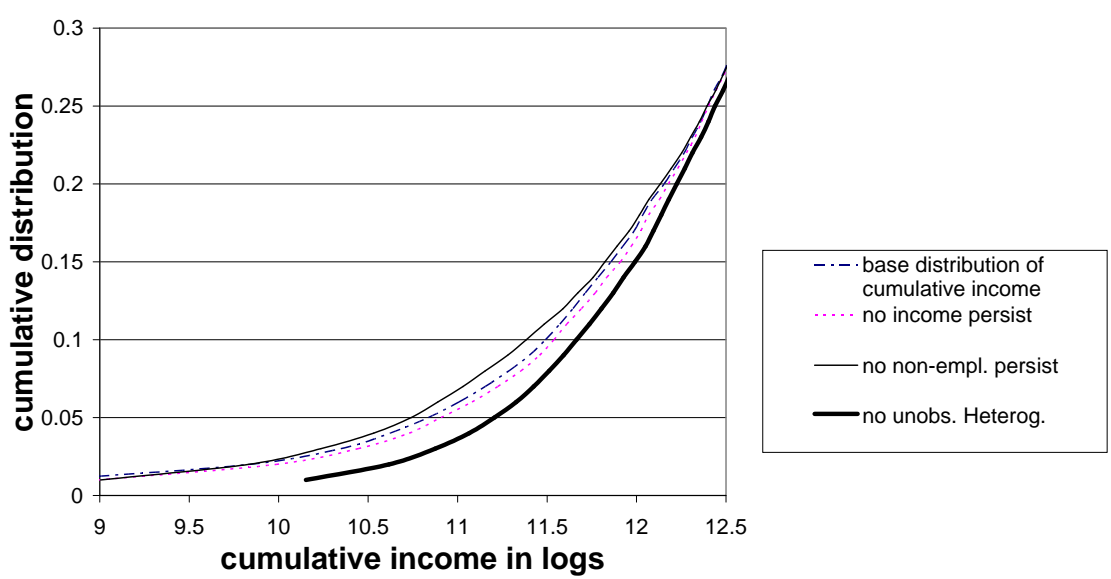

Figure 7. 